\title{
La información parlamentaria en los parlamentos regionales en España: evaluación de las sedes web $y$ presencia en los medios sociales
}

\author{
Daniel Esteban Merino MedinA \\ Parlamento Regional de Extremadura \\ dmerino@asambleaex.es \\ Antonio MuÑOZ CAÑAVATE \\ Universidad de Extremadura \\ amunoz@alcazaba.unex.es
}

Recibido: Febrero 2014

Aceptado: Mayo 2014

Resumen: Desde la aparición de Internet y del World Wide Web los parlamentos han encontrado un cauce eficaz para llegar a los ciudadanos lo que se ha visto aumentado por la Web 2.0 y los nuevos medios sociales que han auspiciado una mayor comunicación con el exterior. Este trabajo presenta un estudio realizado a los parlamentos autonómicos españoles a través de la aplicación de dos recomendaciones de la Unión Interparlamentaria (UIP): las Directrices para sitios web parlamentarios y las Directrices para el uso de los medios sociales de comunicación por los parlamentos. El estudio se ha llevado a cabo a través de un cuestionario basado en dichas recomendaciones y los datos se han extraído por observación en las páginas web.

Palabras clave: Gestión de información; Información parlamentaria; documentación legislativa; medios sociales; Administración electrónica; democracia participativa

\section{Parliamentary information in regional parliaments in Spain: evaluation of web presence and social media sites}

\begin{abstract}
Since the advent of the Internet and the World Wide Web, parliaments have found them to be an effective channel through which to reach citizens. This has been enhanced by the so-called Web 2.0 with its new social media that have facilitated more communication with the outside. This paper presents a study applied to Spain's Autonomous Community (regional) parliaments with the implementation of two recommendations of the Inter-Parliamentary Union (IPU): Guidelines for Parliamentary Websites, and Guidelines for the Use of Social Communication Media by Parliaments. The study instrument was a questionnaire based on these recommendations, and by observation of all the corresponding Web pages.
\end{abstract}

Keywords: Information management; parliamentary information; legislative documentation; social media; e-government; participatory democracy 
"La única forma posible de que perduren valores tales como la confianza y la prudencia es a través de un estrecho contacto" Winston Churchill

\section{INTRODUCCIÓN}

Los cambios sociales experimentados desde finales del siglo XX, sustentados por los profundos cambios tecnológicos, han dado lugar a una nueva forma de concebir la relación con la política por parte de los ciudadanos. Esta nueva relación exige otro tipo de comunicación de los ciudadanos con la Administración y con los poderes políticos ${ }^{1}$, una relación basada en una mayor transparencia y una mayor participación de los ciudadanos en el proceso decisorio, demandándose una democracia más participativa.

Respecto a la transparencia de las instituciones públicas, aunque la norma estatal más reciente es la Ley 19/2013, de 9 de diciembre, de transparencia, acceso a la información pública y buen gobierno, en España se ha producido una evolución en las últimas décadas que tiene su origen en la Constitución de $1978^{2}$, y posteriormente en la Ley de procedimiento administrativo de 1992 (Ley 30/1992, de 26 de noviembre, de Régimen Jurídico de las Administraciones Públicas y del Procedimiento Administrativo Común) que ya establecía en distintos artículos varios derechos de los ciudadanos, como el acceso a los registros y archivos de las Administraciones Públicas, y la posibilidad de realizar los trámites y comunicaciones con la Administración a través de los medios electrónicos.

A partir de entonces, y paralelo al desarrollo tecnológico que conlleva la aparición de las redes telemáticas y con ello el acceso de los ciudadanos a la información, se desarrolla la Administración electrónica y diferentes normas que adecuan esta nueva realidad al marco legal. La Ley de firma electrónica (Ley 59/2003), permite mejorar los trámites de ciudadanos y empresas con los organismos públicos, mientras la Ley 11/2007, de 22 de junio, de acceso electrónico de los ciudadanos a los Servicios

${ }^{1}$ Un dato significativo extraído del informe "La Sociedad de la Información en España 2012" es que solo el 5\% de los internautas en España contacta con políticos o partidos políticos. La Sociedad de la Información en España 2012, p. 51. Disponible en:

$<$ http://e-libros.fundacion.telefonica.com/sie12/aplicacion_sie/ParteA/pdf/SIE_2012.pdf $>$. [Consulta: 07-05-2013].

${ }^{2}$ Ya la Constitución de 1978 presenta en su desarrollo algunos artículos como el 105 b, que refleja la necesidad de regular el acceso de los ciudadanos a los archivos y registros administrativos, con la excepción de aquellos aspectos relativos a la seguridad del Estado, la averiguación de los delitos y la intimidad de las personas. 
Públicos, más conocida como la Ley de la Administración electrónica, sienta las bases de una mayor transparencia, en tanto que la Ley obliga a las Administraciones a ofrecer sus servicios por medios telemáticos, pasando del "podrá hacerse" al "deberá hacerse" si el ciudadano lo desea.

El sector público español desde estos años asume los principios del movimiento open data ${ }^{3}$, al desarrollar proyectos para hacer más visible toda su información. La Ley 37/2007, de 16 de noviembre, sobre Reutilización de la Información del Sector Público ${ }^{4}$ es en España una norma básica para hacer más transparente y accesible la información del sector público que es definida en la propia Ley como: "Toda información cualquiera que sea su soporte material o electrónico, así como su forma de expresión, gráfica, sonora o en imagen utilizada incluyendo en consecuencia, también los datos en sus niveles más desagregados o en bruto que haya sido elaborado o custodiado por cualquiera de los órganos $\mathrm{u}$ organismos de la Administración Pública". A nivel nacional el Gobierno español pone en marcha en 2009 el Proyecto Aporta, dentro del Plan Avanza con el objetivo de promover la cultura de reutilización de la información en el ámbito de la Administración pública, que en 2010 crea el Catálogo de Información Pública, como un punto de acceso único a las fuentes de datos disponibles del sector público estatal. En octubre de 2011 se lanza la iniciativa datos.gob.es, que toma el relevo del Proyecto Aporta y asume su compromiso con la apertura de la información del sector público. Organiza y gestiona el Catálogo de Información Pública del sector público.

Anterior a la entrada en vigor de la mencionada Ley de Transparencia, dos leyes regulaban aspectos específicos: la Ley 27/2006 el acceso a la información en materia de medio ambiente, y la Ley 14/2010 sobre la información geográfica en España.

En este contexto de transparencia encontramos a los medios sociales, que si bien son anteriores a la aparición del World Wide Web, irrumpen con fuerza en torno a $2008^{5}$. El sector público y la clase política han comenzado a utilizar

${ }^{3}$ La Fundación Telefónica editó en 2010 la publicación "La sociedad de la información en España 2010", describiendo así este concepto: "en el año 2010 ha comenzado la explosión del movimiento Open Data consistente en la puesta a disposición de la sociedad de manera libre de gran cantidad de datos procedentes de diferentes organizaciones, fundamentalmente del ámbito de la Administración Pública o de aquellos proyectos que han sido financiados con dinero público o creados por una institución pública. En general, los datos proporcionados suelen estar en formato no-textual y tratan sobre diferentes temáticas (médicos, geográficos, metereológicos, sobre biodiversidad, relativos a servicios públicos, etc.)".

${ }^{4}$ La Ley transpone la Directiva 2003/98/CE del Parlamento Europeo y del Consejo, de 17 de noviembre de 2003, relativa a la reutilización de la información del sector público.

${ }^{5}$ Entre estos medios encontramos a las listas de correo electrónico, utilizadas incluso por redes que competían con Internet, y a los grupos de noticias de Usenet de los que posteriormente se haría cargo Google. Algunos trabajos que presentan a principios de los años noventa estos medios son: 
medios sociales masivamente. Posiblemente Twitter sea el ejemplo más explícito. También lo han hecho los parlamentos, que han encontrado en este medio social una manera de fomentar la participación de los ciudadanos en los debates políticos y en la adopción de decisiones. Según el Informe Mundial de 2012 sobre Parlamento electrónico, la tercera parte de los parlamentos están en los medios sociales y otra tercera parte está en vías de incorporación (Naciones Unidas, 2012). En 2013 la Unión Interparlamentaria (UIP) ha preparado las "Directrices para el uso de los medios sociales de comunicación por los parlamentos" para animar a estas instituciones a utilizar estos medios de modo efectivo, eficaz y general, con el fin de fortalecer la vinculación entre parlamento y ciudadanos, consolidando así la democracia, al hacerla más participativa.

Este contexto de apertura de la información de las instituciones del sector público a los ciudadanos enmarca el trabajo que se presenta a continuación enfocado a conocer la información de los parlamentos regionales españoles. Para ello se ha realizado una aproximación a la información parlamentaria y los sistemas creados para colaborar en este ámbito entre las distintas instituciones. Se presentan, después, aquellos trabajos similares que se han realizado, previos a este estudio, y finalmente se expone el trabajo realizado.

\section{LA INFORMACIÓN DEL SECTOR PARLAMENTARIO}

La documentación que nos interesa estudiar es la generada en los parlamentos, la documentación legislativa (parlamentaria). A su vez, dentro de la documentación parlamentaria, podemos distinguir entre:

1. La generada en el proceso de elaboración de leyes, y es objeto de publicación oficial, como: Constitución y Leyes.

Esta documentación se publica en los boletines oficiales, ya sea el Boletín Oficial del Estado o los boletines oficiales y diarios de sesiones de las distintas Comunidades autónomas.

2. Y la que genera la institución parlamentaria para su funcionamiento, compuesta por:

BAIGET, Tomas, HÍPOLA, Pedro y MUÑOZ CAÑAVATE, Antonio. "Iwetel: the Spanish (electronic) connection". FID News Bulletin, 1994, nº 9, vol. 45, pp. 271-273; HÍPOLA RUIZ, Pedro, BAIGET, Tomás y MUÑOZ-CAÑAVATE, Antonio. "Iwetel: Foro electrónico para los profesionales de la Documentación". En IV Jornadas Españolas de Documentación Automatizada. 1994, octubre, 6-8, Gijón, pp. 27-33; y MUÑOZ-CAÑAVATE, Antonio y CASTRO CASTRO, Carlos. "Recursos informativos en Internet: Foros electrónicos de discusión”. En IV Jornadas Españolas de Documentación Automatizada. 1994, octubre, 6-8, Gijón, pp. 63-75. 
- Iniciativas parlamentarias relativas a la función de control y dirección política: investidura del Gobierno, mociones de censura y cuestiones de confianza, interpelaciones, mociones, preguntas y comparecencias, proposiciones no de ley, elección de personas y nombramientos, etc.

- Iniciativas de orientación: debates monográficos, debates de política general, comparecencias y presentación de planes.

- Iniciativas de impulso: propuestas de impulso, propuestas de pronunciamiento y resoluciones.

- Documentación sobre Régimen interior.

- Concursos y contratos.

Esta documentación se publica en los boletines oficiales de los parlamentos y en los diarios de sesiones.

Los Boletines Oficiales de los parlamentos recogen textos y documentos del trabajo parlamentario, así como todos los documentos relacionados con la actividad parlamentaria. Difunden todos los textos que requieran la publicación por precepto reglamentario, o son necesarios para la tramitación de las iniciativas o son ordenados por el Presidente del Parlamento

Y los Diarios de Sesiones recogen los debates parlamentarios en las sesiones de Plenos y Comisiones.

\subsection{LA COLABORACIÓN PARLAMENTARIA EN MATERIA DE INFORMACIÓN}

La colaboración parlamentaria española en materia de información se beneficia de dos iniciativas: Red_Parlamenta (Sistema Integral de Intercambio de Información Parlamentaria), y el Grupo Español de Archivos y Archiveros Parlamentarios y de Partidos Políticos (SPP-ICA).

\subsubsection{RED PARLAMENTA}

Red Parlamenta se gestó en mayo del 2009, en el seno de las XI Jornadas Españolas de Documentación, a iniciativa de los profesionales de los servicios de información de tres parlamentos autonómicos, los de Castilla y León, País Vasco y Cataluña. En el mes de diciembre se presentó la versión Beta al resto de servicios de información de los parlamentos autonómicos. Rápidamente la gran mayoría de profesionales participaron en el proyecto, introduciendo contenidos y utilizando la plataforma para intercambiar información y conocimiento, convirtiéndose en poco tiempo en una herramienta muy bien valorada por los profesionales. 
En la Conferencia de Presidentes de los Parlamentos Autonómicos de España (COPREPA) celebrada el mes de mayo del 2010 en la Asamblea de Extremadura, se recoge la idea de "Impulsar la puesta en marcha de una plataforma de intercambio de información parlamentaria". En la reunión de la COPREPA celebrada en Pamplona el 2011, se adopta Red_Parlamenta como plataforma de intercambio de información, por el hecho de encontrarse ya muy desarrollada y probada su eficacia, y también por su bajo coste. Esto facilitó la elaboración de un convenio que progresivamente firmaron todos los parlamentos regionales. En octubre de 2012, la Sociedad Española de Documentación e Información (SEDIC), en el marco de VII Premio Nacional SEDIC, le otorgó una mención especial de reconocimiento a la calidad e innovación, como la mejor iniciativa emprendedora en gestión de información, al ponerla como ejemplo de "trabajo colaborativo en red y del uso de una buena estrategia de visibilidad".

Es una herramienta de trabajo para los servicios de información parlamentaria y a su vez es una herramienta de consulta para la Administración Parlamentaria. Todavía no está abierta a los ciudadanos, y los contenidos no están indexados por los motores de búsqueda. Entre sus carencias se encuentra la inexistencia de un catálogo colectivo de los fondos bibliográficos de las bibliotecas parlamentarias, aunque si existe un listado con enlaces a los distintos catálogos. Por otra parte, la Guía de contenidos de Red_Parlamenta, estructura en distintos apartados los contenidos de la plataforma ${ }^{6}$.

${ }^{6}$ La plataforma incluye los siguientes apartados:

1. Pantalla de inicio (con tablón de anuncios y consultas).

2. Actividad parlamentaria (información sobre la actividad parlamentaria de los parlamentos participantes). Se pueden encontrar: buscadores de tramitación parlamentaria de cada parlamento, repositorios online de cada parlamento donde se recogen los Boletines y Diarios de Sesiones, últimas iniciativas legislativas, leyes aprobadas en los parlamentos participantes, reglamentos y resoluciones de cada parlamento, normas de personal, y tramitación de las reformas de los Estatutos de Autonomía.

3. Recursos y colecciones (específico en el ámbito de la biblioteconomía y documentación parlamentaria). Entre ellos: OPAC online de cada biblioteca parlamentaria, bases de datos útiles en documentación, listado de revistas disponibles por suscripción en los departamentos y unidades de documentación de los parlamentos y enlaces a recursos para consulta online de legislación internacional.

4. Productos documentales elaborados por los departamentos de biblioteca y documentación de cada Parlamento: dossiers de documentación, boletines de sumarios, boletines de novedades bibliográficas, bibliografías temáticas, guías de recursos.

5. Espacio profesional que recoge información para los profesionales del campo de la información y documentación de los parlamentos: directorio de teléfonos y direcciones de los participantes en Red_Parlamenta, artículos y bibliografía profesional, eventos, histórico de consultas y reuniones Red_Parlamenta.

6. Y apartado del principio de subsidiariedad (en vigor con el Tratado de Lisboa), que contiene recursos sobre el modo de actuación de cada parlamento respecto al mismo principio. 


\subsubsection{GRUPO ESPAÑOL DE ARCHIVOS Y ARCHIVEROS PARLAMENTARIOS Y DE PARTIDOS POLÍTICOS (SPP-ICA)}

El Consejo Internacional de Archivos (ICA), que se dedica a promover la conservación, desarrollo y utilización del patrimonio mundial de los archivos, creó en el Congreso Internacional de Archivos celebrado en Montreal en 1992 la denominada Sección de Archivos y Archiveros Parlamentarios y de Partidos Políticos (SPP-ICA). Dentro de esta Sección se enmarca el Grupo Español.

El Grupo Español celebra reuniones anuales en las sedes parlamentarias españolas, importantes tanto para los profesionales del sector como para la comunidad archivística parlamentaria. Estas reuniones sirven como punto de encuentro de experiencias archivísticas de los profesionales de archivos parlamentarios, así como para la unificación de la normalización de las tareas que comúnmente se desempeñan en dichos archivos especializados.

\section{ESTADO DE LA CUESTIÓN}

En España se han realizado en los últimos años distintos trabajos sobre la información parlamentaria. Así, en 2002, la Revista General de Información y Documentación dedicó un monográfico a la Documentación parlamentaria. Antes varios autores publicaron artículos relacionados con el tema en la Revista de las Cortes Generales.

En 1998 Andoni Iturbe (Iturbe March, 1998) escribió un artículo sobre el acceso a la documentación parlamentaria. Este autor diferencia la documentación parlamentaria de la documentación de la administración parlamentaria, desde dos puntos de vista: material y formal. Iturbe nos habla de la organización del parlamento, distinguiendo todos los órganos unipersonales y colegiados, como fuente de la documentación parlamentaria que se genera. Ya en este trabajo se menciona el efecto del principio de publicidad como medio de difusión de la actividad parlamentaria.

En la Revista de las Cortes Generales, Miguel Angel Gonzalo Rozas e Irene Ramos Vielba publicaron tres artículos (Gonzálo Rojas y Ramos Vielba, 2000; Gonzálo Rojas y Ramos Vielba, 2000b; y Gonzálo Rojas y Ramos Vielba, 2001) sobre la documentación parlamentaria en Internet. Cada uno de estos trabajos se dedicaba a instituciones parlamentarias diferentes en función de su ámbito territorial: el Congreso de los Diputados, las asambleas legislativas de la Comunidades autónomas, y las páginas web de los países de la Unión Europea.

En 2002 Rosa María Grau (Garu Guadix, 2002) publicó un artículo sobre los centros de documentación, centrándose en el Congreso de los Diputados y sobre todo a la difusión de la información, tanto de manera activa como pasiva. En 2006 publicó otro trabajo (Graru Guadix, 2006) sobre la documentación española en 
general, donde ubicaba la documentación parlamentaria dentro de la documentación jurídica, separándola de la jurisprudencia y de la legislación. Por último, la misma autora participó en 2008 en el seminario "Las direcciones de estudios parlamentarias" con una ponencia (Graru Guadix, 2010) donde analizaba el parlamento y la documentación con una perspectiva de futuro.

También Clabo Clemente y Ramos Vielma (2002) estudiaron la presencia de la documentación parlamentaria, tanto en las sedes web del Congreso de los Diputados y Senado como en otras páginas web españolas (tanto universitarias como de distintas Administraciones Públicas).

En el mismo año María del Carmen Marcos y Ana Belén Gil publican un trabajo sobre información parlamentaria autonómica en la red (Marcos y Gil, 2002). En el mismo nos explican el papel de las nuevas tecnologías en la difusión de la información parlamentaria y si a finales de 2001 la información de los sitios web parlamentarios se ajustaba a las pautas aportadas por la Unión Interparlamentaria (UIP). En otro trabajo María Dolores Ayuso y Victoria Martínez Navarro (Ayuso García y Martínez Navarro, 2005) analizaron las sedes web de parlamentos regionales y también se basaron en las Directrices para sedes web de la UIP, aunque fue la primera versión del año 2000, que tiene diferencias respecto a las publicadas en 2009.

Posteriormente María del Carmen Marcos junto con Cristòfol Rovira (2006) publican un estudio siguiendo las recomendaciones de la Unión Interparlamentaria sobre seis parlamentos: Argentina, Australia, Chile, España, Estados Unidos y el Parlamento europeo.

En 2008 se realizan dos trabajos académicos. La tesis de fin de máster realizada por Assumpta Policarpo Andrés (2008) titulada "La gestión de la información legislativa y parlamentaria en la Comunidad Valenciana. Un estudio interinstitucional (1983-2007)", uno de los estudios más completos realizados recientemente, aunque centrado en las instituciones políticas de la Comunidad Valenciana. Y el trabajo fin de carrera de Martínez Garzón (2008) donde hizo una evaluación de las sedes web parlamentarias autonómicas españolas, aunque más centrada en el análisis descriptivo de los buscadores y bases de datos. A dichos trabajos hay que sumar los estudios de Yolanda Martín González en el contexto de la Unión Europea (Martín González, 2002).

Por otra parte, entre 2004 y 2008 Eva Campos Domínguez realiza un estudio sobre la ciberdemocracia en el Congreso de los Diputados (Campos Domínguez, 2011), en el marco de una tesis doctoral defendida en 2009, donde analiza empíricamente la información e interacción en las sedes web de parlamentos españoles. Este análisis se efectúa sobre la información que publican los parlamentos en sus páginas web, tanto información institucional como actividad parlamentaria. Así mismo, estudia las herramientas de interacción entre los parlamentos con los ciudadanos. 
Actualmente el Grupo de Trabajo e-Democracia de la CALRE (Conferencia de los Presidentes de los Parlamentos de los Estados Legislativos de Europa) ha publicado un informe del estudio comparado sobre e-Democracia en los Parlamentos de la CALRE, dentro del Plan de Trabajo de dicho grupo, examinando la situación actual, para realizar una propuesta de mejoras y compromiso. Para ello se han analizado las fases de la e-Democracia que muestran la participación e interacción entre parlamentos y ciudadanos: 1. información, 2. eConsulta, 3. e-Participación y 4. e-Voto.

Entre las conclusiones del informe se aprecia una buena puntuación sobre los bloques temáticos estudiados relativos a la información dada sobre la institución, órganos y diputados de la mayoría de los parlamentos. Aunque se podrían mejorar aspectos como las estadísticas web, emisiones en directo, recopilaciones normativas, información relacionada con la actividad diaria de los diputados, etc.

Tanto las fases de e-consulta como la de e-voto obtienen una puntuación baja y aquí es donde deberían mejorar y plantearse como reto para el futuro. Sobre la fase de e-participación, con buenos resultados en redes sociales y participación ciudadana, se debe mejorar la participación ciudadana en el procedimiento legislativo mediante foros online y videoconferencias. Por último, el informe valora positivamente el acercamiento de los jóvenes a la política, y se recomienda una mayor actividad divulgativa de los parlamentos en centros educativos, organización de debates y conferencias y, sobre todo, acercar a los parlamentarios de forma activa a estos centros y dar a conocer la labor de servicio público que realizan, pudiendo utilizar para ello las nuevas tecnologías.

Posteriormente a la recogida de datos que se presenta en este trabajo, en febrero de 2014 la organización no gubernamental Transparencia Internacional España (Transparencia Internacional, 2014) ha publicado el Índice de Transparencia de los Parlamentos (IPAR), mediante el cual se evalúa el nivel de transparencia de los parlamentos autonómicos y se pretende impulsar la publicación de información parlamentaria interesante para el ciudadano y la sociedad.

Finalmente Irene Ramos Vielba (2014) publica un trabajo donde realiza una comparativa de la incorporación de las nuevas tecnologías y herramientas 2.0 por parte de las asambleas legislativas autonómicas en sus sedes web, analizando el grado de apertura conseguido en la última década. Así mismo, estudia la presencia institucional en las redes sociales y la participación ciudadana en los procesos legislativos, así como los mecanismos de comunicación con los ciudadanos. Es coincidente con nuestro trabajo cuando estudia la "información y contenidos" de las web parlamentarias, basándose también en las Directrices de la UIP (2009).

\section{METODOLOGÍA Y RESULTADOS}

Los resultados que se exponen en este artículo se centran en la fase informativa. Se describe cómo los parlamentos autonómicos ofrecen la 
información y documentación parlamentaria en sus contenidos de las sedes web, como información general, debates parlamentarios, información sobre los diputados y órganos de la Cámara en la web, legislación e información legislativa de las iniciativas parlamentarias, etc.

Para realizar este estudio se ha partido de las recomendaciones de la UIP revisadas en 2009, que actualmente son el único documento de referencia para la elaboración de sedes web (entre cuyas características resaltan la facilidad de acceso a la web, al contenido informativo que ofrecen y a la capacidad de búsqueda que proporcionan). La Unión Interparlamentaria es una organización internacional de parlamentos creada en 1889 como punto de encuentro del diálogo parlamentario internacional y con el objetivo de promover la paz y la democracia representativa mediante la cooperación. Esta organización trabaja en estrecha cooperación con las Naciones Unidas, cuyos objetivos comparte, y quien le otorga en 2002 el status de observador permanente. La forman 164 parlamentos miembros - de los cinco continentes- y diez miembros asociados, entre los que está el Parlamento Europeo.

Estas Directrices para sitios web parlamentarios tienen como objetivo proporcionar recomendaciones generales y prácticas que faciliten las tareas de planificación y gestión de páginas web parlamentarias, permitiendo que los parlamentos den pautas a los diseñadores y gestores de las sedes web, sin distinguir a los parlamentos por sus características y tipologías. Dichas recomendaciones deben adaptarse a la gran diversidad de parlamentos que existen a nivel mundial, cada uno con unas características concretas, y un nivel de desarrollo tecnológico diferente.

El objetivo de este artículo es plasmar una imagen fija de la publicación de la información en sedes web y medios sociales por los parlamentos autonómicos. Para ello la aplicación del cuestionario se realizó por observación en el periodo comprendido entre mayo y junio de 2013, sobre la sede web de las diecisiete sedes web de los parlamentos autonómicos españoles como fuente de información hacia el exterior, dejando de lado la información disponible en las intranets parlamentarias al no tener acceso a estos recursos desde el punto de vista del ciudadano.

Las pautas de la UIP de 2009 recogen seis secciones o áreas:

1 Información general sobre el parlamento.

2 Información sobre las actividades legislativas, presupuestarias y de control.

3 Herramientas de búsqueda, recepción y visualización de información.

4 Herramientas de comunicación y diálogo con los ciudadanos.

5 Diseño en función de la utilidad, la accesibilidad y el idioma.

Gestión. 
Las sedes web de los parlamentos, autonómicos en nuestro caso, constituyen herramientas importantes tanto para los diputados como para los órganos parlamentarios y para el personal de la Cámara. Suelen ser la herramienta más rápida y fiable para conseguir información sobre tramitación de proyectos de ley, para visualizar programas y agenda, para obtener documentación de comisiones, y para conocer las intervenciones de diputados en plenos y comisiones. La información que difunden los parlamentos a través de sus portales es consultada por los usuarios del propio parlamento (diputados, grupos parlamentarios, órganos y administración parlamentaria), pero también en gran parte está dirigida a los ciudadanos (medios de comunicación, estudiantes, investigadores, profesionales y ciudadanos en general).

La información más sensible o de acceso restringido se ofrece a través de la intranet parlamentaria.

Desde las recomendaciones de la UIP del año 2000 hasta su revisión en 2009, las sedes web parlamentarias son más complejas y exigentes. No solo se ofrece información básica, sino que también se permite obtener textos oficiales de las iniciativas parlamentarias. Con la aparición e implantación de la web 2.0, ha sido necesario agregar herramientas para fomentar la comunicación bidireccional entre los parlamentarios y los ciudadanos, dándoles la posibilidad de participar en el proceso político. También se han mejorado los motores de búsqueda y los servicios de alerta para encontrar intervenciones y documentos específicos. Cada vez más, pueden familiarizarse con el parlamento a través de diversos medios, tales como grabaciones en audio y vídeo difundidas por Internet, ya sea en directo o en archivos facilitados a pedido. Además han mejorado el diseño para que sean comprensibles y fáciles de usar, y han mejorado su accesibilidad para ponerlos al alcance de todos, incluidas las personas con discapacidad.

Respecto a las diferencias entre las recomendaciones del 2009 con las anteriores, se ha suprimido la distinción entre directrices recomendadas y opcionales que incluía la edición de 2000 de la UIP. Consideramos que todas las directrices son recomendadas si las normas y procedimientos del parlamento permiten aplicarlas.

La tabla 1 recoge las pautas aplicadas al estudio de los parlamentos autonómicos, divididas en cinco secciones (aunque las directrices de la UIP constan de seis, está última - sobre la gestión, el control y las responsabilidades no podía evaluarse en todas las sedes web parlamentarias por la dificultad en la obtención de los datos, ya que había que realizarla mediante cuestionario directo al responsable de los contenidos de la sede web y no mediante la observación como método empleado en la extracción de datos).

Cada sección disponía de un número limitado de subsecciones y éstas a su vez de distintos indicadores que se recogen en anexo, y que han sido los puntuados de la siguiente forma: 
a) 1 punto si la información del indicador está publicada en la web del parlamento.

b) Y 0 puntos si no se publica la información en la web del parlamento.

Tabla 1. Criterios para el análisis de las sedes web de los parlamentos autonómicos

\begin{tabular}{|c|c|c|c|}
\hline Secciones & Subsecciones & $\begin{array}{l}\text { Puntuación } \\
\text { máxima por } \\
\text { subsección }\end{array}$ & $\begin{array}{l}\text { Puntuación } \\
\text { máxima por } \\
\text { sección }\end{array}$ \\
\hline \multirow{11}{*}{$\begin{array}{l}\text { Sección } 1- \\
\text { información general } \\
\text { sobre el parlamento }\end{array}$} & 1.1. Acceso al Parlamento & 4 & \multirow[t]{11}{*}{50} \\
\hline & $\begin{array}{l}1.2 \text { Historia y papel del } \\
\text { Parlamento }\end{array}$ & 3 & \\
\hline & $\begin{array}{l}1.3 \text { Funciones, composición y } \\
\text { actividades }\end{array}$ & 7 & \\
\hline & 1.4. Cargos directivos electos & 3 & \\
\hline & $\begin{array}{l}1.5 \text { Comisiones y Comités } \\
\text { parlamentarios y órganos no } \\
\text { plenarios }\end{array}$ & 7 & \\
\hline & 1.6 Legisladores & 7 & \\
\hline & $\begin{array}{l}\text { 1.7 Partidos Políticos en el } \\
\text { Parlamento }\end{array}$ & 2 & \\
\hline & $\begin{array}{l}1.8 \text { Elecciones y sistemas } \\
\text { electorales }\end{array}$ & 5 & \\
\hline & $\begin{array}{l}\text { 1.9 Administración del } \\
\text { Parlamento }\end{array}$ & 2 & \\
\hline & $\begin{array}{l}\text { 1.10 Publicaciones, } \\
\text { documentos y servicios de } \\
\text { información }\end{array}$ & 3 & \\
\hline & $\begin{array}{l}\text { 1.11 Enlaces generales con } \\
\text { otros sitios web }\end{array}$ & 7 & \\
\hline \multirow{4}{*}{$\begin{array}{l}\text { Sección } 2- \\
\text { información sobre } \\
\text { actividades } \\
\text { legislativas, } \\
\text { presupuestarias y de } \\
\text { control }\end{array}$} & $\begin{array}{l}\text { 2.1 Información general sobre } \\
\text { actividades (legislativa, } \\
\text { presupuestaria y de control) }\end{array}$ & 5 & \multirow[t]{4}{*}{31} \\
\hline & 2.2 Proceso legislativo & 6 & \\
\hline & $\begin{array}{l}\text { 2.3 Financiación del } \\
\text { presupuesto (la financiación } \\
\text { del presupuesto/ financiación } \\
\text { pública corresponde a la } \\
\text { recepción de ingresos y } \\
\text { asignación de fondos públicos) }\end{array}$ & 6 & \\
\hline & $\begin{array}{l}2.4 \text { Control (preguntas, } \\
\text { respuestas, réplicas, } \\
\text { declaraciones, informes de } \\
\text { comisiones de investigación, } \\
\text { interpelaciones y debates } \\
\text { especiales) }\end{array}$ & 5 & \\
\hline
\end{tabular}




\begin{tabular}{|c|c|c|c|}
\hline & $\begin{array}{l}2.5 \text { Actividades de las } \\
\text { comisiones y comités } \\
\text { parlamentarios y de otros } \\
\text { órganos no plenarios }\end{array}$ & 5 & \\
\hline & $\begin{array}{l}\text { 2.6 Actividades plenarias y } \\
\text { documentación }\end{array}$ & 4 & \\
\hline \multirow{5}{*}{$\begin{array}{l}\text { Sección } 3 \text { - } \\
\text { Herramientas: } \\
\text { búsqueda, recepción y } \\
\text { visualización de } \\
\text { información }\end{array}$} & 3.1 Motor de búsqueda & 5 & \multirow[t]{5}{*}{11} \\
\hline & $\begin{array}{l}3.2 \text { Transmisión por radio, } \\
\text { televisión e Internet }\end{array}$ & 2 & \\
\hline & 3.3 Servicio de alertas & 1 & \\
\hline & 3.4 Servicios móviles & 1 & \\
\hline & 3.5 Seguridad y autentificación & 2 & \\
\hline \multirow{2}{*}{$\begin{array}{l}\text { Sección } 4- \\
\text { Herramientas: } \\
\text { comunicación y } \\
\text { diálogo con los } \\
\text { ciudadanos }\end{array}$} & 4.1 Comentarios y opiniones & 2 & \multirow[t]{2}{*}{7} \\
\hline & $\begin{array}{l}\text { 4.2 Comunicación entre } \\
\text { diputados y ciudadanos }\end{array}$ & 5 & \\
\hline \multirow{4}{*}{$\begin{array}{l}\text { Sección 5 - Diseño: } \\
\text { usabilidad, } \\
\text { accesibilidad e idioma }\end{array}$} & 5.1 Usabilidad & 2 & \multirow[t]{4}{*}{8} \\
\hline & 5.2 Normas de accesibilidad & 1 & \\
\hline & 5.3 Idiomas & 3 & \\
\hline & $\begin{array}{l}\text { 5.4 Elementos generales del } \\
\text { diseño }\end{array}$ & 2 & \\
\hline
\end{tabular}

Los datos reflejados en este estudio muestran la realidad de esas fechas. La importancia de la imagen política que proyectan los parlamentos, la aplicación de la ley estatal de transparencia (aprobada meses después) y de distintas leyes regionales similares, a la vez que la actualización constante de las páginas que hacen ganar en calidad y cantidad siguiendo las recomendaciones de la UIP, permite prever una continua mejora de los portales.

Para los trabajos referentes al uso de los medios sociales en los parlamentos nos hemos basado en las nuevas directrices de la Unión Interparlamentaria (UIP) para los medios sociales, "Directrices para el uso de los medios sociales de comunicación por los parlamentos" (2013) con las que se pretende generalizar el uso de los medios sociales mejorando su eficacia y eficiencia. Fueron elaboradas por la citada UIP, con el apoyo de la Asociación de Secretarios Generales de Parlamentos (ASGP), la división de la Federación Internacional de Asociaciones de Bibliotecarios y Bibliotecas (IFLA) destinada a las bibliotecas y los servicios de investigación de los parlamentos, y del Centro Global para las TICS en los Parlamentos.

Estas directrices están destinadas al personal de los parlamentos que intervienen en el uso institucional de los medios sociales (también pueden hacer uso de ellas los parlamentarios, aunque no están dirigidas a ellos específicamente) y tienen una doble pretensión: 
a) Aprovechar las nuevas posibilidades de comunicación e interacción que ofrecen los medios sociales.

b) Reconocer la importancia de saber gestionar y dirigir los medios sociales en el contexto general de los parlamentos.

\subsection{RESULTADOS SEGÚN LAS PAUTAS DE LA UNIÓN INTERPARLAMENTARIA PARA LA FASE INFORMATIVA}

\subsubsection{DATOS GLOBALES PARA TODOS LOS PARLAMENTOS}

Es importante señalar que el $100 \%$ de los parlamentos autonómicos dispone de sede web, mientras que en 2002 y según Marcos y Gil (2002), todos los parlamentos estaban presentes en Internet menos el Parlamento de La Rioja.

La tabla 2 y la figura 1 presentan los resultados globales para las cinco secciones evaluadas según las normas de la UIP. De una media nacional de 57,94 puntos sobre los 107 puntos de máximo se puede comprobar que nueve de los parlamentos autonómicos superan esa media: Madrid, Aragón, Valencia, Andalucía, Cataluña, Extremadura, Galicia, Navarra y País Vasco.

Tabla 2. Valoración general de sedes web de parlamentos autonómicos

\begin{tabular}{|c|c|c|c|c|c|c|c|}
\hline & \multicolumn{7}{|c|}{ GENERAL } \\
\hline & SECCIÓN $1^{\mathrm{a}}$ & SECCIÓN $2^{\mathrm{a}}$ & SECCIÓN $3^{\mathrm{a}}$ & SECCIÓN $4^{\mathrm{a}}$ & SECCIÓN $5^{\circ}$ & TOTAL & MAXMO \\
\hline Asamblea de Madrid & 33 & 13 & 5 & 1 & 7 & 59 & 107 \\
\hline Asamblea Regional de Murcia & 27 & 7 & 2 & 2 & 0 & 38 & 107 \\
\hline Cortes de Aragón & 30 & 17 & 7 & 3 & 1 & 58 & 107 \\
\hline Cortes de Castilla y León & 24 & 15 & 4 & 1 & 2 & 46 & 107 \\
\hline Cortes de Castilla-La Mancha & 28 & 15 & 2 & 1 & 1 & 47 & 107 \\
\hline Cortes Valencianas & 35 & 18 & 6 & 5 & 7 & 71 & 107 \\
\hline Junta General del Principado de Asturias & 22 & 11 & 4 & 1 & 4 & 42 & 107 \\
\hline Parlamento de Andalucía & 40 & 19 & 7 & 5 & 6 & 77 & 107 \\
\hline Parlamento de Canarias & 35 & 10 & 3 & 4 & 2 & 54 & 107 \\
\hline Parlamento de Cantabria & 33 & 17 & 3 & 4 & 0 & 57 & 107 \\
\hline Parlamento de Cataluña & 41 & 23 & 11 & 6 & 8 & 89 & 107 \\
\hline Parlamento de Extremadura & 34 & 15 & 10 & 5 & 4 & 68 & 107 \\
\hline Parlamento de Galicia & 29 & 19 & 6 & 6 & 7 & 67 & 107 \\
\hline Parlamento de La Rioja & 18 & 10 & 3 & 0 & 5 & 36 & 107 \\
\hline Parlamento de las Islas Baleares & 25 & 12 & 2 & 1 & 2 & 42 & 107 \\
\hline Parlamento de Navarra & 33 & 22 & 9 & 4 & 6 & 74 & 107 \\
\hline Parlamento Vasco & 28 & 16 & 8 & 2 & 6 & 60 & 107 \\
\hline MEDIA & 30,29 & 15,24 & 5,41 & 3,00 & 4,00 & 57,94 & \\
\hline
\end{tabular}


Figura 1. Gráfico de la valoración general de sedes web de parlamentos autonómicos

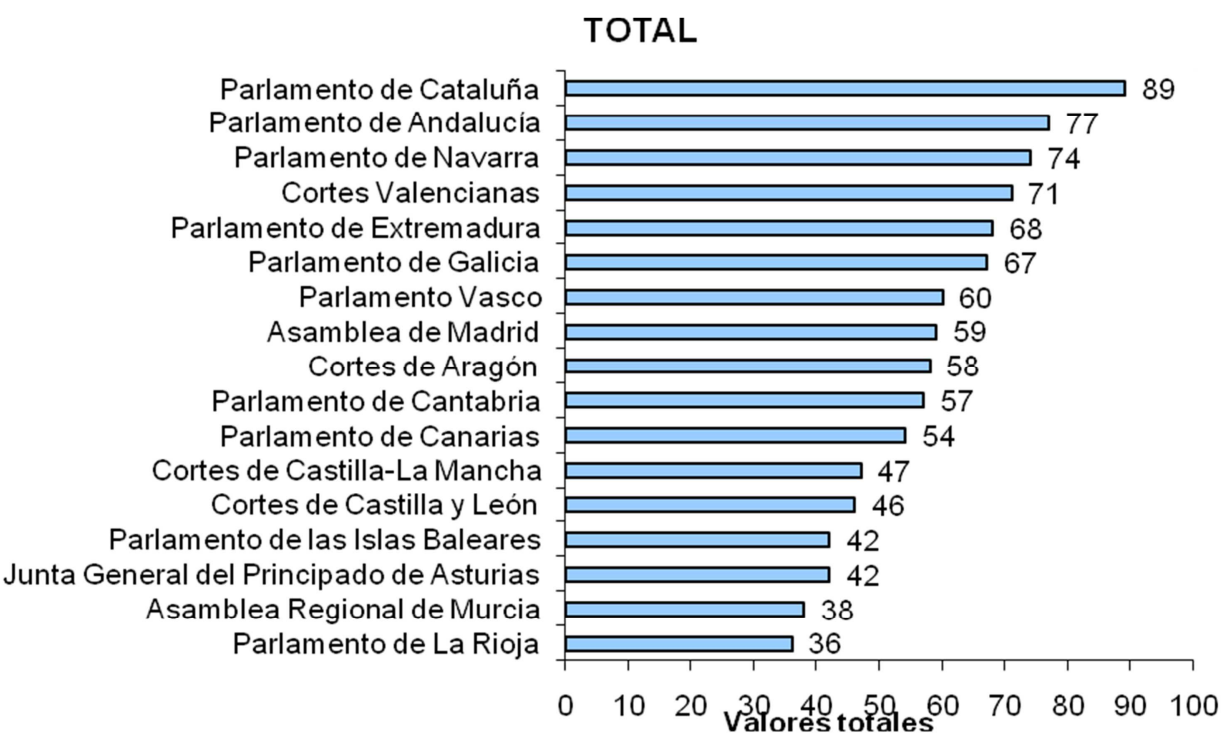

\subsubsection{SECCIÓN $1^{\mathrm{a}}$. INFORMACIÓN GENERAL SOBRE EL PARLAMENTO}

Las sedes web constituyen uno de los medios más importantes para permitir a los ciudadanos informarse acerca de su parlamento: su historia, su trabajo y sus legisladores. Estas recomendaciones se centran en cómo los parlamentos pueden mostrarse a los ciudadanos representados de una manera directa y sencilla.

En la siguiente tabla (tabla 3) se observan las puntuaciones obtenidas por los parlamentos autonómicos en esta sección.

Los parlamentos autonómicos que consiguieron la mayor puntuación en esta Sección $1^{\mathrm{a}}$ en los cuestionarios y, por tanto, se ajustan más a las recomendaciones de la UIP de 2009 son: el Parlamento de Cataluña, el Parlamento de Andalucía, las Cortes Valencianas y el Parlamento de Canarias. Todos ellos junto con los de Extremadura, Madrid, Cantabria y Navarra superan la media de 30,29 puntos.

En la mayor parte de los parlamentos existen carencias en la subsección 1.3 del cuestionario "Funciones, composición y actividades". Los parlamentos no ofrecen información sobre presupuestos y dotación de personal, ni tampoco informes anuales de los plenos y comisiones. También hay falta de información en la subsección 1.6 "Legisladores", siendo difícil encontrar datos sobre los diputados. Habitualmente se ofrece información de las comisiones a las que pertenecen y cargos que ostentan. 
Tabla 3. Valores Sección $1^{\mathrm{a}}$. Información general sobre el Parlamento

\begin{tabular}{|c|c|c|c|c|c|c|c|c|c|c|c|c|c|}
\hline \multicolumn{14}{|c|}{ SECCIÓN $1^{2}$} \\
\hline & $\begin{array}{l}1.1 \text { Acceso } \\
\text { al } \\
\text { Parlamento }\end{array}$ & $\begin{array}{l}\text { 1.2 Historia } \\
\text { y papel del } \\
\text { Parlamento }\end{array}$ & $\begin{array}{l}1.3 \\
\text { Funciones, } \\
\text { composición y } \\
\text { actividades }\end{array}$ & $\begin{array}{l}\text { 1.4 Cargos } \\
\text { directivos } \\
\text { electos }\end{array}$ & $\begin{array}{l}1.5 \\
\text { Órganos } \\
\text { no } \\
\text { plenarios }\end{array}$ & $\begin{array}{l}1.6 \\
\text { Legisladores }\end{array}$ & $\begin{array}{l}\text { 1.7 Partidos } \\
\text { políticos en el } \\
\text { Parlamento }\end{array}$ & $\begin{array}{l}1.8 \\
\text { Elecciones } \\
\text { y sistemas } \\
\text { electorales }\end{array}$ & $\begin{array}{l}1.9 \\
\text { Administraci } \\
\text { ón del } \\
\text { Parlamento }\end{array}$ & $\begin{array}{l}1.10 \\
\text { Publicaciones, } \\
\text { documentos y } \\
\text { servicios de } \\
\text { informacion }\end{array}$ & $\begin{array}{l}1.11 \\
\text { Enlaces } \\
\text { generales a } \\
\text { otros sitios } \\
\text { web }\end{array}$ & TOTAL & MÁXMO \\
\hline Asamblea de Madrid & 4 & 3 & 4 & 2 & 5 & 5 & 2 & 3 & 1 & 2 & 2 & 33 & 50 \\
\hline Asamblea Regional de Murcia & 2 & 3 & 3 & 3 & 3 & 2 & 2 & 2 & 1 & 2 & 4 & 27 & 50 \\
\hline Cortes de Aragón & 4 & 2 & 4 & 2 & 3 & 3 & 1 & 2 & 2 & 1 & 6 & 30 & 50 \\
\hline Cortes de Castilla y León & 4 & 3 & 4 & 3 & 2 & 1 & 2 & 4 & 0 & 1 & 0 & 24 & 50 \\
\hline Cortes de Castilla-La Mancha & 3 & 3 & 4 & 3 & 2 & 3 & 0 & 3 & 1 & 0 & 6 & 28 & 50 \\
\hline Cortes Valencianas & 4 & 3 & 4 & 3 & 3 & 3 & 1 & 4 & 0 & 3 & 7 & 35 & 50 \\
\hline Junta General del Principado de Asturias & 3 & 3 & 1 & 3 & 2 & 3 & 0 & 1 & 1 & 1 & 4 & 22 & 50 \\
\hline Parlamento de Andalucía & 4 & 3 & 4 & 3 & 5 & 6 & 2 & 4 & 1 & 3 & 5 & 40 & 50 \\
\hline Parlamento de Canarias & 3 & 3 & 2 & 3 & 4 & 4 & 2 & 5 & 1 & 1 & 7 & 35 & 50 \\
\hline Parlamento de Cantabria & 4 & 3 & 5 & 3 & 4 & 4 & 0 & 3 & 1 & 1 & 5 & 33 & 50 \\
\hline Parlamento de Cataluña & 4 & 3 & 4 & 3 & 6 & 5 & 2 & 4 & 1 & 2 & 7 & 41 & 50 \\
\hline Parlamento de Extremadura & 4 & 1 & 6 & 2 & 3 & 6 & 1 & 3 & 1 & 1 & 6 & 34 & 50 \\
\hline Parlamento de Galicia & 3 & 3 & 4 & 3 & 0 & 3 & 2 & 5 & 0 & 0 & 6 & 29 & 50 \\
\hline Parlamento de La Rioja & 2 & 2 & 1 & 2 & 2 & 2 & 0 & 3 & 1 & 0 & 3 & 18 & 50 \\
\hline Parlamento de las Islas Baleares & 3 & 3 & 4 & 1 & 3 & 2 & 0 & 5 & 0 & 0 & 4 & 25 & 50 \\
\hline Parlamento de Navarra & 4 & 3 & 6 & 2 & 3 & 4 & 1 & 4 & 1 & 2 & 3 & 33 & 50 \\
\hline Parlamento Vasco & 2 & 2 & 5 & 1 & 2 & 5 & 2 & 2 & 1 & 0 & 6 & 28 & 50 \\
\hline MEDIA & 3,35 & 2,71 & 3,82 & 2,47 & 3,06 & 3,59 & 1,18 & 3,35 & 0,82 & 1,18 & 4,76 & 30,29 & \\
\hline
\end{tabular}

Figura 2. Gráfico de valores Sección $1^{\mathrm{a}}$. Información general

\section{Sección $1^{\text {a }}$. Información general}

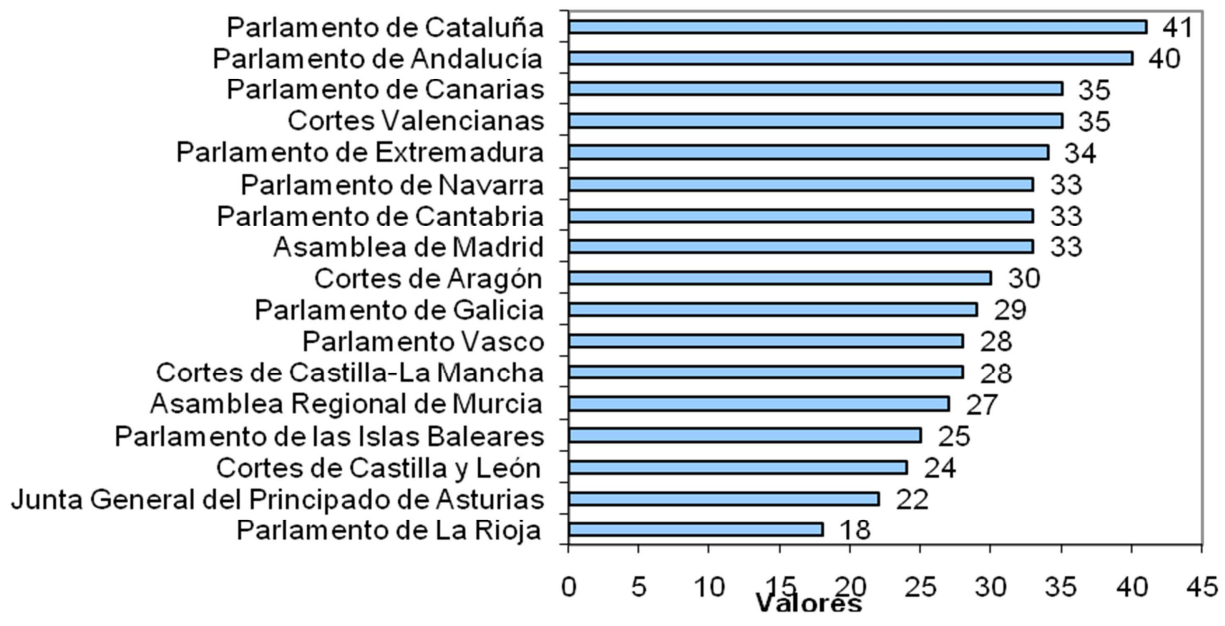




\subsubsection{SECCIÓN $2^{\circ}$. INFORMACIÓN SOBRE LAS ACTIVIDADES LEGISLATIVAS, PRESUPUESTARIAS Y DE CONTROL}

La importancia del trabajo de parlamentario tiene que ver con sus responsabilidades legislativas, presupuestarias y de control. Estas actividades pueden variar de un parlamento a otro, y las recomendaciones tienen por objeto abarcar las tres áreas, sin la necesidad de ser aplicables en la misma medida.

En la Sección 2 se describen estas actividades de forma más pormenorizada que en la Sección 1. También se incluyen recomendaciones sobre los documentos y otro tipo de información, organizados primero según el proceso por el que son generados - legislativo, de control, y de examen y aprobación del presupuesto - y después según las organizaciones que los producen (las comisiones y la sesión plenaria).

Tabla 4. Valoración Sección $2^{\text {a }}$. Información sobre actividades legislativas, presupuestaria y de control

\begin{tabular}{|c|c|c|c|c|c|c|c|c|}
\hline \multicolumn{9}{|c|}{ SECCIÓN $2^{\mathrm{a}}$} \\
\hline & $\begin{array}{l}2.1 \text { Información } \\
\text { general sobre } \\
\text { actividades }\end{array}$ & $\begin{array}{l}\text { 2.2 Proceso } \\
\text { legislativo }\end{array}$ & $\begin{array}{l}2.3 \\
\text { Financiación } \\
\text { del } \\
\text { presupuesto }\end{array}$ & 2.4 Control & $\begin{array}{l}2.5 \\
\text { Actividades } \\
\text { de órganos } \\
\text { no plenarios }\end{array}$ & $\begin{array}{l}\text { 2.6 Actividades plenarias y } \\
\text { documentación }\end{array}$ & TOTAL & MÁXIMO \\
\hline Asamblea de Madrid & 1 & 2 & 0 & 4 & 3 & 3 & 13 & 31 \\
\hline Asamblea Regional de Murcia & 2 & 3 & 1 & 1 & 0 & 0 & 7 & 31 \\
\hline Cortes de Aragón & 2 & 3 & 4 & 4 & 2 & 2 & 17 & 31 \\
\hline Cortes de Castilla y León & 3 & 3 & 3 & 0 & 3 & 3 & 15 & 31 \\
\hline Cortes de Castilla-La Mancha & 2 & 5 & 1 & 1 & 3 & 3 & 15 & 31 \\
\hline Cortes Valencianas & 3 & 4 & 0 & 3 & 4 & 4 & 18 & 31 \\
\hline Junta General del Principado de Asturias & 2 & 3 & 1 & 3 & 1 & 1 & 11 & 31 \\
\hline Parlamento de Andalucía & 4 & 3 & 1 & 3 & 4 & 4 & 19 & 31 \\
\hline Parlamento de Canarias & 2 & 4 & 1 & 3 & 0 & 0 & 10 & 31 \\
\hline Parlamento de Cantabria & 3 & 3 & 2 & 4 & 2 & 3 & 17 & 31 \\
\hline Parlamento de Cataluña & 5 & 4 & 1 & 5 & 4 & 4 & 23 & 31 \\
\hline Parlamento de Extremadura & 2 & 1 & 1 & 4 & 3 & 4 & 15 & 31 \\
\hline Parlamento de Galicia & 3 & 4 & 2 & 4 & 3 & 3 & 19 & 31 \\
\hline Parlamento de La Rioja & 1 & 3 & 1 & 3 & 1 & 1 & 10 & 31 \\
\hline Parlamento de las Islas Baleares & 4 & 4 & 0 & 2 & 1 & 1 & 12 & 31 \\
\hline Parlamento de Navarra & 4 & 5 & 4 & 5 & 2 & 2 & 22 & 31 \\
\hline Parlamento Vasco & 2 & 3 & 4 & 3 & 2 & 2 & 16 & 31 \\
\hline MEDIA & 2,65 & 3,35 & 1,59 & 3,06 & 2,24 & 2,35 & 15,24 & \\
\hline
\end{tabular}

Interpretando los datos de la siguiente figura (figura 3) observamos que salvo el Parlamento de Cataluña y el Parlamento de Navarra, que son los que logran mayor puntuación, muchos parlamentos rondan la media nacional $(15,24$ puntos). Con menores puntuaciones se encuentran los parlamentos de Murcia (sólo 7 puntos), y La Rioja con 10, seguidos por los parlamentos de Navarra, Islas Baleares y Asturias.

La subsección 2.3 del cuestionario "Financiación del presupuesto" es una de las que tienen mayores carencias en los sitios web, dejando en evidencia una 
gran opacidad con los datos presupuestarios y de financiación. Solamente aparecen las leyes de presupuestos, sin un mayor detalle y seguimiento del desarrollo de dichas leyes.

Figura 3. Gráfico Valoración Sección 2a . Información sobre actividades legislativas, presupuestaria y de control

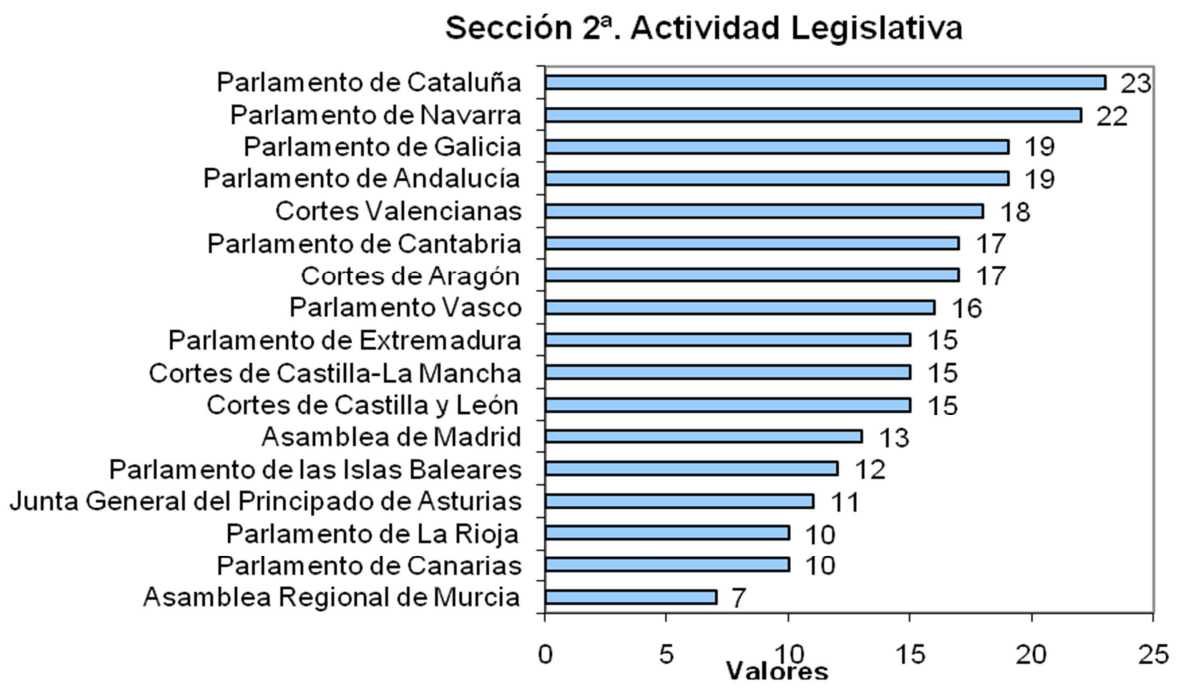

\subsubsection{SECCIÓN 3a . HERRAMIENTAS DE BÚSQUEDA, RECEPCIÓN Y VISUALIZACIÓN DE INFORMACIÓN}

En la Sección 3, la UIP realiza una serie de recomendaciones sobre los métodos de búsqueda y visualización de la información, así como los documentos sobre el parlamento y sus miembros. Los motores de búsqueda pueden atender las necesidades de los miembros y los ciudadanos por igual a la hora de realizar búsquedas. Además, cada vez tienen más importancia los diversos métodos de difusión de audio y vídeo por Internet, y los archivos creados con dichas posibilidades. Por último, las recomendaciones señalan la importancia de los servicios de alerta y acceso móvil al sitio web, tanto para los legisladores como para los ciudadanos. Muchos de estos novedosos y prácticos medios de acceso requieren, sin embargo, que también se hagan recomendaciones relativas a la seguridad y la autentificación.

En la siguiente tabla (tabla 5) se observan las puntuaciones obtenidas por los parlamentos autonómicos en esta sección. 
Tabla 5. Valoración Sección $3^{\mathrm{a}}$. Herramientas: búsqueda, recepción y visualización de la información

\begin{tabular}{|c|c|c|c|c|c|c|c|}
\hline \multicolumn{8}{|c|}{ SECCIÓN $3^{a}$} \\
\hline & $\begin{array}{l}\text { 3.1 Motor de } \\
\text { búsqueda }\end{array}$ & $\begin{array}{l}3.2 \\
\text { Transmisión } \\
\text { por radio, } \\
\text { televisión e } \\
\text { internet }\end{array}$ & $\begin{array}{l}\text { 3.3 Servicios } \\
\text { de alerta }\end{array}$ & $\begin{array}{l}3.4 \text { Servicios } \\
\text { móviles }\end{array}$ & $\begin{array}{l}3.5 \text { Seguridad } \\
\text { y } \\
\text { autentificación }\end{array}$ & TOTAL & MÁXIMO \\
\hline Asamblea de Madrid & 2 & 2 & 0 & 0 & 1 & 5 & 11 \\
\hline Asamblea Regional de Murcia & 0 & 0 & 0 & 0 & 2 & 2 & 11 \\
\hline Cortes de Aragón & 3 & 2 & 1 & 0 & 1 & 7 & 11 \\
\hline Cortes de Castilla y León & 1 & 2 & 1 & 0 & 0 & 4 & 11 \\
\hline Cortes de Castilla-La Mancha & 1 & 1 & 0 & 0 & 0 & 2 & 11 \\
\hline Cortes Valencianas & 2 & 2 & 1 & 0 & 1 & 6 & 11 \\
\hline Junta General del Principado de Asturias & 3 & 1 & 0 & 0 & 0 & 4 & 11 \\
\hline Parlamento de Andalucía & 4 & 2 & 1 & 0 & 0 & 7 & 11 \\
\hline Parlamento de Canarias & 2 & 0 & 1 & 0 & 0 & 3 & 11 \\
\hline Parlamento de Cantabria & 0 & 2 & 1 & 0 & 0 & 3 & 11 \\
\hline Parlamento de Cataluña & 5 & 2 & 1 & 1 & 2 & 11 & 11 \\
\hline Parlamento de Extremadura & 5 & 2 & 1 & 0 & 2 & 10 & 11 \\
\hline Parlamento de Galicia & 4 & 2 & 0 & 0 & 0 & 6 & 11 \\
\hline Parlamento de La Rioja & 1 & 1 & 0 & 0 & 1 & 3 & 11 \\
\hline Parlamento de las Islas Baleares & 0 & 2 & 0 & 0 & 0 & 2 & 11 \\
\hline Parlamento de Navarra & 4 & 2 & 1 & 0 & 2 & 9 & 11 \\
\hline Parlamento Vasco & 5 & 2 & 1 & 0 & 0 & 8 & 11 \\
\hline MEDIA & 2,47 & 1,59 & 0,59 & 0,06 & 0,71 & 5,41 & \\
\hline
\end{tabular}

Interpretando los datos de la siguiente figura (figura 4) observamos que el Parlamento de Cataluña con un $100 \%$ de la puntuación cumple con todas recomendaciones y el Parlamento de Extremadura cumple todas ellas salvo el apartado 3.4 que versa sobre la utilización de servicios que permiten a legisladores y público acceder a información y documentos del sitio web en dispositivos móviles. Este servicio exclusivamente lo presta el Parlamento de Cataluña. Por abajo se encuentran con solo dos puntos los parlamentos de Murcia, Castilla-La Mancha e Islas Baleares.

No disponen de motor de búsqueda los parlamentos de Cantabria, Islas Baleares y Murcia, siendo muy difícil encontrar información parlamentaria en todos ellos.

Prácticamente todos los sitios web, menos los de Murcia y Canarias, disponen de retransmisión en directo del video y audio de las sesiones o en su lugar un archivo de estos eventos donde consultarlos a demanda.

En el campo de la seguridad y la autentificación es donde deben incidir en un futuro estas instituciones, dando acceso a los miembros de los parlamentos a documentos confidenciales. Así mismo debe implementarse la firma digital para autenticar la información y documentación parlamentaria. 
Figura 4. Gráfico Valoración Sección $3^{\mathrm{a}}$. Herramientas de búsqueda, recepción y visualización de información

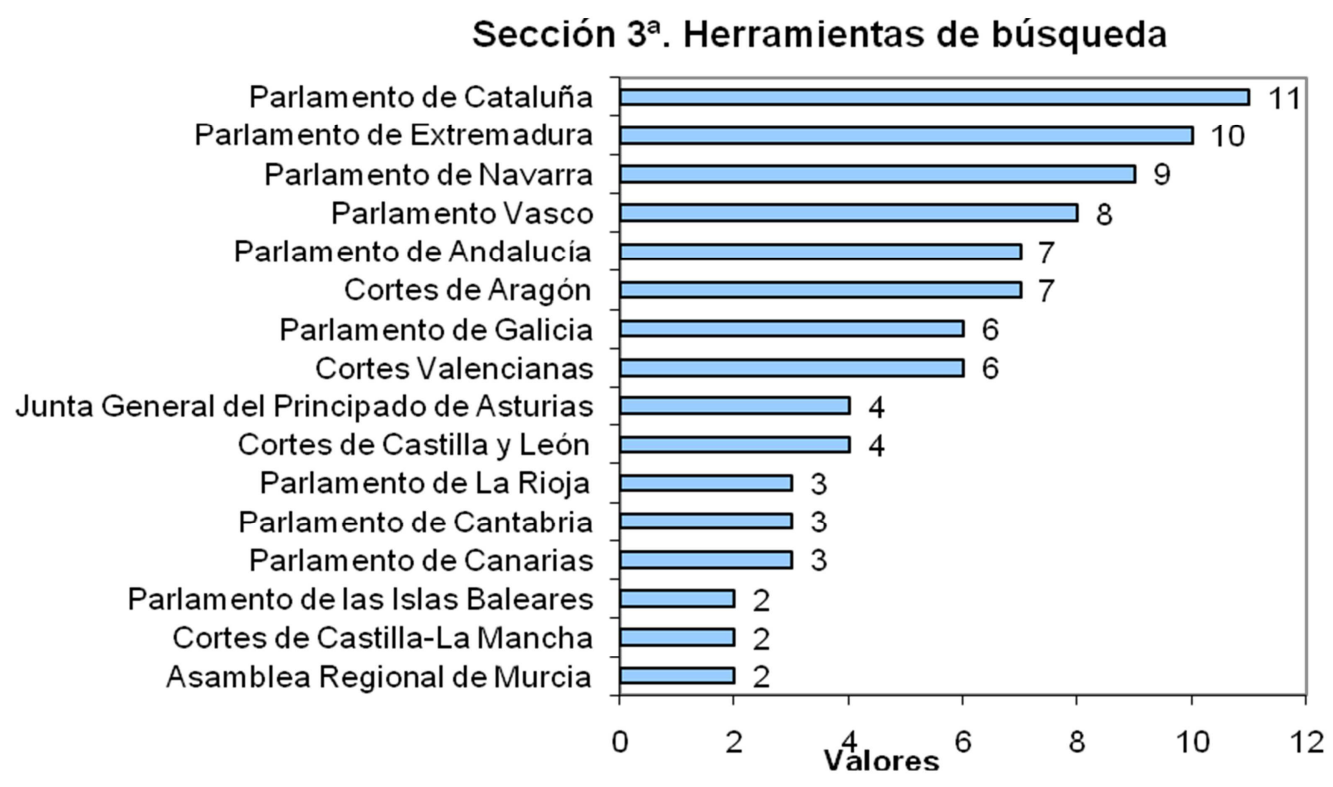

\subsubsection{SECCIÓN $4^{\circ}$. HERRAMIENTAS DE COMUNICACIÓN Y DIÁLOGO CON LOS CIUDADANOS}

El aumento de los usos de comunicación a través de Internet, que facilitan el diálogo entre ciudadanos y sus representantes, ha dado lugar a que la Unión Interparlamentaria haya realizado recomendaciones sobre la disponibilidad de distintas herramientas en la sede web. Las recomendaciones evaluadas en esta sección se dividen en dos subsecciones: comentarios y opiniones; y comunicación entre diputados y ciudadanos.

En la siguiente tabla (tabla 6) se observan las puntuaciones obtenidas por los parlamentos autonómicos en esta sección. 
Tabla 6. Valoración Sección $4^{\mathrm{a}}$. Herramientas: comunicación y diálogo con los ciudadanos

\begin{tabular}{|c|c|c|c|c|}
\hline \multicolumn{5}{|c|}{ SECCIÓN 4a } \\
\hline & $\begin{array}{l}\text { 4.1 Comentarios y } \\
\text { opiniones }\end{array}$ & $\begin{array}{l}4.2 \text { Comunicación } \\
\text { entre diputados y } \\
\text { ciudadanos }\end{array}$ & TOTAL & MÁXIMO \\
\hline Asamblea de Madrid & 1 & 0 & 1 & 7 \\
\hline Asamblea Regional de Murcia & 1 & 1 & 2 & 7 \\
\hline Cortes de Aragón & 0 & 3 & 3 & 7 \\
\hline Cortes de Castilla y León & 0 & 1 & 1 & 7 \\
\hline Cortes de Castilla-La Mancha & 0 & 1 & 1 & 7 \\
\hline Cortes Valencianas & 2 & 3 & 5 & 7 \\
\hline Junta General del Principado de Asturias & 1 & 0 & 1 & 7 \\
\hline Parlamento de Andalucía & 2 & 3 & 5 & 7 \\
\hline Parlamento de Canarias & 2 & 2 & 4 & 7 \\
\hline Parlamento de Cantabria & 1 & 3 & 4 & 7 \\
\hline Parlamento de Cataluña & 2 & 4 & 6 & 7 \\
\hline Parlamento de Extremadura & 2 & 3 & 5 & 7 \\
\hline Parlamento de Galicia & 2 & 4 & 6 & 7 \\
\hline Parlamento de La Rioja & 0 & 0 & 0 & 7 \\
\hline Parlamento de las Islas Baleares & 1 & 0 & 1 & 7 \\
\hline Parlamento de Navarra & 2 & 2 & 4 & 7 \\
\hline Parlamento Vasco & 0 & 2 & 2 & 7 \\
\hline MEDIA & 1,12 & 1,88 & 3,00 & \\
\hline
\end{tabular}

Los parlamentos de Cataluña y Galicia son los más valorados en esta sección (figura 5), cumpliendo casi todas las recomendaciones menos la que destacamos como una de las carencias apreciadas en todos los sitios web parlamentarios, que es la inexistencia de sistemas que permitan votaciones en línea cuando el tema sea importante y los resultados útiles para los ciudadanos (subsección 4.2 del cuestionario).

Otra de las carencias generalizadas es la carencia de una herramienta que permita a diputados, comisiones, funcionarios recibir, administrar y responder a correos electrónicos de ciudadanos y sociedad civil. 
Figura 5. Gráfico Valoración Sección 4a . Herramientas de comunicación

\section{Sección $4^{a}$. Herramientas de comunicación}

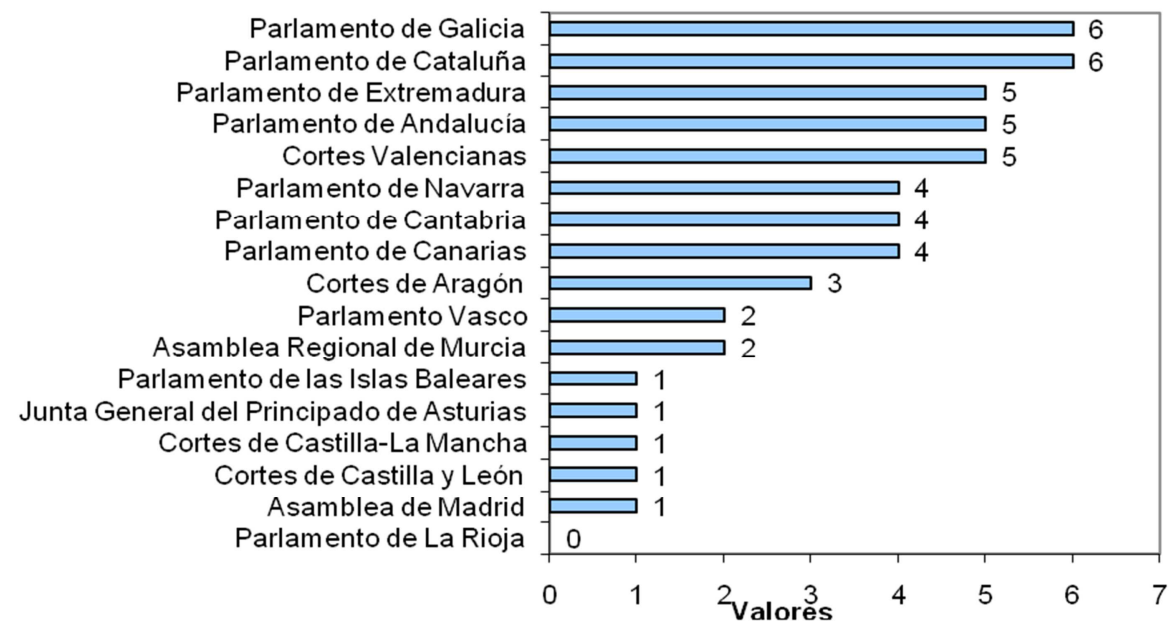

\subsubsection{SECCIÓN 5․ DISEÑO: USABILIDAD, ACCESIBILIDAD E IDIOMA}

En esta sección, la UIP formula recomendaciones sobre distintos temas que faciliten el uso de las sedes web. En la tabla 7 se observan las puntuaciones obtenidas por los parlamentos autonómicos en esta sección.

Tabla 7. Valoración Sección $5^{\text {a }}$. Diseño: usabilidad, accesibilidad e idiomas

\begin{tabular}{|c|c|c|c|c|c|c|}
\hline \multicolumn{7}{|c|}{ SECCIÓN $5^{a}$} \\
\hline & 5.1 Usabilidad & 5.2 Normas de accesibilidad & 5.3 Idiomas & $\begin{array}{l}\text { 5.4 Elementos } \\
\text { generales del diseño }\end{array}$ & TOTAL & MÁXIMO \\
\hline Asamblea de Madrid & 2 & 1 & 2 & 2 & 7 & 8 \\
\hline Asamblea Regional de Murcia & 0 & 0 & 0 & 0 & 0 & 8 \\
\hline Cortes de Aragón & 1 & 0 & 0 & 0 & 1 & 8 \\
\hline Cortes de Castilla y León & 0 & 1 & 0 & 1 & 2 & 8 \\
\hline Cortes de Castilla-La Mancha & 0 & 0 & 0 & 1 & 1 & 8 \\
\hline Cortes Valencianas & 1 & 1 & 3 & 2 & 7 & 8 \\
\hline Junta General del Principado de Asturias & 1 & 1 & 0 & 2 & 4 & 8 \\
\hline Parlamento de Andalucía & 2 & 1 & 1 & 2 & 6 & 8 \\
\hline Parlamento de Canarias & 0 & 1 & 0 & 1 & 2 & 8 \\
\hline Parlamento de Cantabria & 0 & 0 & 0 & 0 & 0 & 8 \\
\hline Parlamento de Cataluña & 2 & 1 & 3 & 2 & 8 & 8 \\
\hline Parlamento de Extremadura & 2 & 1 & 0 & 1 & 4 & 8 \\
\hline Parlamento de Galicia & 2 & 1 & 2 & 2 & 7 & 8 \\
\hline Parlamento de La Rioja & 1 & 1 & 1 & 2 & 5 & 8 \\
\hline Parlamento de las Islas Baleares & 0 & 0 & 2 & 0 & 2 & 8 \\
\hline Parlamento de Navarra & 0 & 1 & 3 & 2 & 6 & 8 \\
\hline Parlamento Vasco & 1 & 1 & 2 & 2 & 6 & 8 \\
\hline MEDIA & 0,88 & 0,71 & 1,12 & 1,29 & 4,00 & \\
\hline
\end{tabular}


En la figura 6 se observa que el Parlamento de Cataluña es el único que cumple con todas las directrices de las subsecciones (8), seguido de los parlamentos de Madrid, Comunidad Valenciana y Galicia (7). La media nacional está en el cumplimiento de la mitad de los requerimientos (4).

Respecto a los idiomas hay que realizar una aclaración en esta sección. En principio los parlamentos que no disponen de otra lengua oficial que no sea el español tienen valor cero. Pero en este estudio valoramos el esfuerzo de algunos parlamentos como el de Cataluña que además de sus lenguas oficiales -el catalán y el aranés- dispone de versiones en otros idiomas oficiales del territorio nacional aunque no está obligado a ello, como son el aranés, el euskera y el gallego.

Figura 6. Gráfico Valoración Sección $5^{\mathrm{a}}$. Diseño

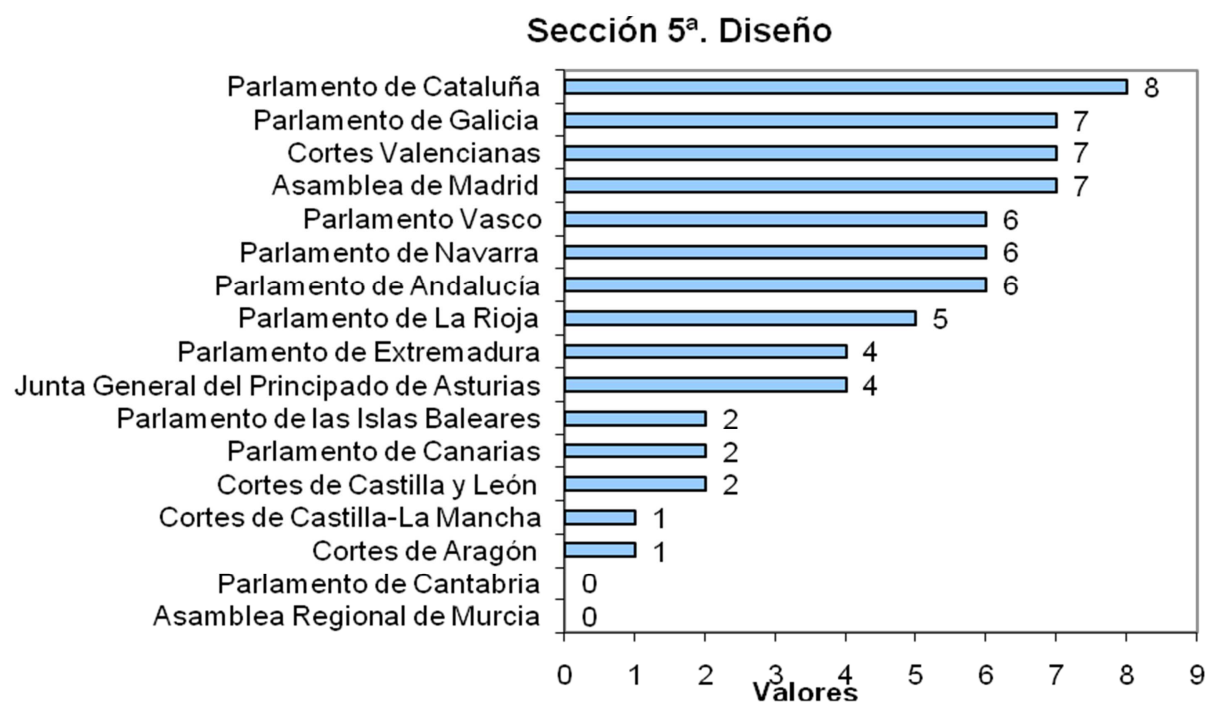

\subsection{RESULTADOS SEGÚN LAS DIRECTRICES DE LA UIP PARA EL USO DE LOS MEDIOS SOCIALES}

Una de las premisas de los parlamentos es hacer participar a los ciudadanos fomentando su intervención en el debate político y en la adopción de decisiones. Para ello los medios sociales de comunicación son una herramienta que contribuye a estrechar lazos entre los parlamentos y los ciudadanos. Esta estrecha relación sirve tanto para los parlamentos (institución) como para los parlamentarios, y facilitan la comunicación e interacción con el ciudadano, de tal forma que se eleva el nivel de transparencia.

Para evaluar la presencia de los parlamentos autonómicos españoles en los medios sociales se ha realizado una encuesta por observación, basada en las 
Directrices para medios sociales de la Unión Interparlamentaria mencionada en la metodología. Se han verificando los perfiles institucionales de los parlamentos en los distintos medios y redes sociales más conocidos, como LinkedIn, Facebook, Twitter y Youtube, entre otros.

Tabla 8. Parlamentos en los medios sociales

\begin{tabular}{|c|c|c|c|c|c|c|c|c|}
\hline & & & MEDIOS SC & CIALES & & & & \\
\hline & FACEBOOK & TWITTER & YOUTUBE & FLICKR & LINKEDIN & PINTEREST & GOOGLE+ & TOTALES \\
\hline Asamblea de Madrid & 1 & 0 & 0 & 0 & 0 & 0 & 0 & 1 \\
\hline Asamblea Regional de Murcia & 0 & 0 & 1 & 0 & 0 & 0 & 0 & 1 \\
\hline Cortes de Aragón & 1 & 1 & 1 & 1 & 0 & 0 & 0 & 4 \\
\hline Cortes de Castilla y León & 1 & 1 & 0 & 0 & 0 & 0 & 1 & 3 \\
\hline Cortes de Castilla-La Mancha & 0 & 0 & 0 & 0 & 0 & 0 & 0 & 0 \\
\hline Cortes Valencianas & 1 & 1 & 1 & 1 & 0 & 0 & 0 & 4 \\
\hline Junta General del Principado de Asturias & 0 & 0 & 0 & 0 & 0 & 0 & 0 & 0 \\
\hline Parlamento de Andalucía & 1 & 1 & 1 & 0 & 0 & 0 & 0 & 3 \\
\hline Parlamento de Canarias & 1 & 1 & 0 & 0 & 1 & 0 & 0 & 3 \\
\hline Parlamento de Cantabria & 1 & 1 & 0 & 1 & 0 & 0 & 1 & 4 \\
\hline Parlamento de Cataluña & 1 & 1 & 1 & 0 & 0 & 0 & 0 & 3 \\
\hline Parlamento de Extremadura & 3 & 1 & 1 & 1 & 0 & 0 & 0 & 6 \\
\hline Parlamento de Galicia & 1 & 1 & 0 & 0 & 0 & 0 & 0 & 2 \\
\hline Parlamento de La Rioja & 0 & 0 & 0 & 0 & 0 & 0 & 0 & 0 \\
\hline Parlamento de las Islas Baleares & 0 & 0 & 0 & 0 & 0 & 0 & 0 & 0 \\
\hline Parlamento de Navarra & 0 & 1 & 0 & 0 & 0 & 0 & 0 & 1 \\
\hline Parlamento Vasco & 1 & 1 & 1 & 1 & 0 & 0 & 0 & 4 \\
\hline TOTAL & 13 & 11 & 7 & 5 & 1 & 0 & 2 & \\
\hline
\end{tabular}

En las fechas de realización del estudio, solamente el Parlamento de Canarias tenía perfil oficial en Linkedin. Lo cual es comprensible ya que esta red ha tenido hasta fechas recientes un enfoque casi exclusivamente profesional.

Respecto al resto de medios sociales es muy insignificante la presencia de Meneame o de Google+ (sólo dos parlamentos se encontraban en Google +, Castilla y León y Cantabria). Mientras en el ámbito de la compartición de imágenes Flickr ganaba la partida a Pinterest, aunque sólo cinco instituciones parlamentarias hacían uso de este medio: Aragón, Comunidad Valenciana, Cantabria, Extremadura y País Vasco. Los parlamentos de Asturias y Extremadura fueron los pioneros en Flickr, iniciando su actividad en 2010.

\section{CONCLUSIONES}

Del estudio realizado de las sedes web de los parlamentos autonómicos españoles y del uso de los medios sociales de comunicación que hacen los mismos, podemos extraer las siguientes consideraciones a modo de conclusión:

- Sección $1^{\mathrm{a}}$. Los parlamentos regionales cada vez más ofrecen información general de la institución en su sede web como resultado de ese interés aperturista que prevalece en la actualidad. Aún está por mostrar información 
más clara sobre los legisladores y sobre el funcionamiento interno de la institución, sobre todo de la administración interna del parlamento, aspecto que cambiará a corto plazo con la aplicación de las normas de transparencia y buen gobierno que se están aprobando tanto a nivel nacional como regional.

- Sección $2^{\text {a }}$. No está clara aún la información aportada por los parlamentos regionales relativa al proceso legislativo. Los parlamentos deben ser más transparentes a la hora de ofrecer información general sobre sus actividades y sobre el procedimiento legislativo. Deben ofrecer explicaciones claras y entendibles sobre la financiación de los presupuestos generales y su fiscalización, así como de todas las iniciativas de control al gobierno.

- Sección $3^{\mathrm{a}}$. Debe mejorarse el trabajo informático y tecnológico en los parlamentos regionales, sobre todo en las herramientas de búsqueda, recepción y visualización de la información. En el periodo de realización del estudio quedaba mucho por hacer, en relación a los servicios de alerta, aplicaciones móviles y principalmente en la seguridad y autentificación. Por otra parte se ha conseguido un buen nivel de desarrollo en la transmisión vía televisión e Internet de reuniones parlamentarias y eventos oficiales.

- Sección 4a . Respecto a las herramientas de comunicación y diálogo con los ciudadanos, hay un especial interés en mejorar la comunicación entre diputados y ciudadanos, que hasta ahora ha sido inexistente. Este reto se lo han planteado en la actualidad todos los parlamentos regionales y los medios sociales están siendo el principal recurso para conseguir este objetivo. También las epeticiones, canal importante de comunicación con los ciudadanos.

- Sección 5a. Queda mucho por hacer en el campo de la usabilidad y accesibilidad, para que las sedes web sean comprensibles y accesibles a cualquier persona con discapacidad. Respecto a los idiomas en los que se muestran los parlamentos en su sede web, debería plantearse mostrar la información en el idioma oficial internacional más utilizado, el inglés.

- Los parlamentos autonómicos pretenden imponer un modelo proactivo para mejorar los servicios de información, con una adaptación plena de las tecnologías de la información y la comunicación, afectando a sus estructuras y procedimientos y a su vez propiciando la interacción entre administraciónciudadano, promoviendo el concepto de e-Democracia.

- La imagen ha ganado peso en las sedes web y es habitual encontrar emisiones en directo de las sesiones parlamentarias, o un archivo con imágenes fijas o móviles de los eventos institucionales celebrados. Con ello se gana en inmediatez al publicarse en la web y siendo accesible para todos y desde cualquier lugar.

- Está en estudio en varios parlamentos la implantación de la gestión integral de los expedientes parlamentarios, lo que ayudará en el día a día de los 
órganos y servicios de la Cámara, facilitando una colaboración transversal entre ellos, eliminando procedimientos y reduciendo tiempos de respuesta.

- Respecto a los medios sociales las redes más utilizadas por los parlamentos autonómicos son Facebook y Twitter. Parlamentos como el de Castilla-La Mancha, Asturias, La Rioja e Islas Baleares no se encuentran en los medios sociales en el momento de realización del estudio. Mientras los parlamentos autonómicos con mayor presencia son los de Aragón, Comunidad Valenciana, Extremadura y País Vasco.

\section{BIBLIOGRAFÍA}

AYUSO GARCÍA, M. D. y MARTÍNEZ NAVARRO, V. (2005). "Gobierno electrónico. Contenidos y organización de las sedes web de los parlamentos autonómicos". Revista Española de Documentación Científica, nº 4, vol. 28, pp. 462-478.

BAIGET, Tomas, HÍPOLA, Pedro y MUÑOZ CAÑAVATE, Antonio (1994). "Iwetel: the Spanish (electronic) connection". FID News Bulletin, no 9, vol. 45, pp. 271-273.

BENACH I PASCUAL, E. (2002). "El valor de la informació per a l'activitat parlamentària [en línea]". BiD: textos universitaris de biblioteconomia $i$ documentació, $\quad \mathrm{n}^{\mathrm{o}} \quad 8 . \quad<\mathrm{http} / / /$ bid.ub.edu/08benach.htm>. [Consulta: 20/01/2014].

CAMPOS DOMÍNGUEZ, Eva. La ciberdemocracia en el Congreso de los Diputados (2004-2008). Madrid: Congreso de los Diputados, 2011.

GONZALO ROJAS, M. A. y RAMOS VIELBA, I. (2000). "La documentación parlamentaria en Internet: (el caso de la página web del Congreso de los Diputados)". Revista de las Cortes Generales, $\mathrm{n}^{\circ}$ 50, pp. 305-330.

GONZALO ROJAS, M. A. y RAMOS VIELBA, I. (2000b). "La documentación parlamentaria en Internet II (el caso de las páginas web de las Asambleas Legislativas de la Comunidades Autónomas)". Revista de las Cortes Generales, $\mathrm{n}^{\mathrm{0}}$ 51, pp. 217-251.

GONZALO ROJAS, M. A. y RAMOS VIELBA, I. (2001). "La documentación parlamentaria en Internet (y III): el caso de las páginas web en los países de la Unión Europea". Revista de las Cortes Generales, n 53, pp. 319-352.

GRARU GUADIX, R. M. (2002). "Centros de documentación y difusión de la información: su aplicación en el Congreso de los Diputados". Revista de las Cortes Generales, $\mathrm{n}^{\mathrm{o}}$ 56, pp. 303-345.

GRARU GUADIX, R. M. (2006). "La documentación española". Revista de las Cortes Generales, $\mathrm{n}^{\mathrm{o}}$ 67, pp. 497-550.

GRARU GUADIX, R. M. (2010). Documentación y parlamento: evolución organizativa y perspectivas de futuro. Las direcciones de estudios 
parlamentarias [seminario celebrado en Vitoria-Gasteiz los días 7 y 8 de octubre de 2008], pp. 115-150.

HÍPOLA RUIZ, Pedro, BAIGET, Tomás y MUÑOZ-CAÑAVATE, Antonio. (1994). "Iwetel: Foro electrónico para los profesionales de la Documentación". En IV Jornadas Españolas de Documentación Automatizada. Octubre, 6-8, Gijón, pp. 27-33.

ITURBE MACH, A. (1998). "Algunas notas sobre el acceso a la documentación parlamentaria". Revista de las Cortes Generales, no 43, pp. 407-428.

MACIÁ, M. y REVIRIEGO, J. (1998). "Introducción general a la documentación jurídica". En: Manual de Documentación Jurídica. Madrid: Editorial Síntesis.

MARCOS, M. C. y GIL GONZÁLEZ, A. B. (2002). "Información parlamentaria autonómica en la Red: Un impulso electrónico a la democracia". El Profesional de la Información, $\mathrm{n}^{\mathrm{0}}$ 2, vol. 11, pp. 91-101.

MARCOS, M. C. y ROVIRA FONTANALS, C. (2006). "Las webs parlamentarias: funciones y elementos de su interfaz en el acceso a la información". Revista Española de Documentación Científica, n ${ }^{\circ}$ 1, vol. 29, pp. 13-35.

MARTÍN GONZÁLEZ, Y. (2002) La documentación y los servicios de información del Parlamento Europeo. Gijón, TREA.

MARTÍNEZ GARZÓN, V. M. (2008). Evaluación de las web parlamentarias autonómicas españolas. Proyecto fin de carrera, $393 \mathrm{p}$.

MUÑOZ-CAÑAVATE, Antonio y CASTRO CASTRO, Carlos (1994). "Recursos informativos en Internet: Foros electrónicos de discusión". En IV Jornadas Españolas de Documentación Automatizada. Octubre, 6-8, Gijón, pp. 63-75.

NACIONES UNIDAS (2012). World e-Parliament Report 2012. $<$ http://www.ictparliament.org/attachements/WePR2012/WePR2012.zip>. [Consulta: 01-04-2013].

PÁEZ MAÑA, J (1994). Bases de datos jurídicos: características, contenido, desarrollo y marco legal. Madrid: Cindoc.

POLICARPO ANDRÉS, A (2008). La gestión de la información legislativa y parlamentaria en la Comunidad Valenciana. Un estudio interinstitucional (1983-2007). Tesis fin de Máster, $121 \mathrm{p}$.

RAMOS VIELMA, I. y CLABO CLEMENTE, N (2002). "Presencia de la documentación parlamentaria en las páginas web españolas". Revista General de Información y Documentación, $\mathrm{n}^{\mathrm{0}}$ 1, vol. 12, pp. 55-92.

RAMOS VIELMA, I. ¿Hacia parlamentos autonómicos 2.0? Un balance comparado. En: Parlamentos Abiertos. Tecnologías y redes para la democracia. Madrid: Congreso de los Diputados, 2014, pp. 278-322.

TRANSPARENCIA INTERNACIONAL ESPAÑA. Índice de Transparencia de los Parlamentos (IPAR) $<$ http://www.transparencia.org.es/IPAR/INDICE_IPAR_2013.htm>. [Consulta: 09-05-2014]. 
UNIÓN INTERPARLAMENTARIA (2009). Directrices para sitios web parlamentarios. Ginebra: Unión Interparlamentaria. $<$ http://www.ipu.org/PDF/publications/web-s.pdf $>$ [Consulta: 22-02-2013]. UNIÓN INTERPARLAMENTARIA (2013). Directrices para el uso de los medios sociales de comunicación por los parlamentos. $<\mathrm{http}$ //www.ipu.org/PDF/publications/SMG2013ES.pdf>. [Consulta: 22-062013].

\section{ANEXO. SECCIONES DE LAS PAUTAS DE LA UNIÓN INTERPARLAMENTARIA 2009}

\begin{tabular}{|c|c|}
\hline \multicolumn{2}{|c|}{ SECCIÓN 1 - INFORMACIÓN GENERAL SOBRE EL PARLAMENTO } \\
\hline \multirow{4}{*}{$\begin{array}{l}1.1 \quad \text { Acceso al Parlamento } \\
\text { Puntuación }(0-1)\end{array}$} & $\begin{array}{l}\text { Acceso edificio, visitas guiadas, acceso a sesiones, } \\
\text { servicios de inf. Abiertos al público }\end{array}$ \\
\hline & Diagrama distribución de escaños \\
\hline & Visita guiada virtual \\
\hline & Organización sitio web \\
\hline \multirow{3}{*}{$\begin{array}{l}1.2 \text { Historia y papel del Parlamento } \\
\text { Puntuación }(0-1)\end{array}$} & Historia del Parlamento \\
\hline & $\begin{array}{l}\text { Papel del Parlamento y responsabilidades } \\
\text { legislativas }\end{array}$ \\
\hline & Texto Constitución y documento fundacional \\
\hline \multirow{7}{*}{$\begin{array}{l}1.3 \text { Funciones, composición y } \\
\text { actividades Puntuación }(0-1)\end{array}$} & $\begin{array}{l}\text { Composición y funciones del Parlamento y } \\
\text { órganos constitutivos }\end{array}$ \\
\hline & Presupuesto y dotación de personal \\
\hline & Calendario de actividades y eventos \\
\hline & $\begin{array}{l}\text { Asambleas parlamentarias regionales e } \\
\text { internacionales a las que pertenece }\end{array}$ \\
\hline & $\begin{array}{l}\text { Informe anual del Parlamento (pleno y } \\
\text { comisiones) }\end{array}$ \\
\hline & $\begin{array}{l}\text { Estadísticas sobre actividades del ejercicio y } \\
\text { anteriores }\end{array}$ \\
\hline & Textos comunicados de prensa oficiales \\
\hline \multirow{3}{*}{$\begin{array}{l}\text { 1.4. Cargos directivos electos Puntuación } \\
(0-1)\end{array}$} & $\begin{array}{l}\text { Biografía y fotografía del Presidente y } \\
\text { predecesores }\end{array}$ \\
\hline & $\begin{array}{l}\text { Descripción de facultades y prerrogativas del } \\
\text { Presidente }\end{array}$ \\
\hline & Nombre de suplentes y Vicepresidentes \\
\hline \multirow{7}{*}{$\begin{array}{l}1.5 \text { Comisiones y Comités parlamentarios } \\
\text { y órganos no plenarios (considerarse junto } \\
\text { a } 2.5 \text { ) Puntuación }(0-1)\end{array}$} & Lista órganos no plenarios con enlaces \\
\hline & Descripción mandato y cometidos por el órgano \\
\hline & Descripción de actividades realizadas \\
\hline & $\begin{array}{l}\text { Integrantes y nombre del Presidente de cada } \\
\text { órgano no plenario }\end{array}$ \\
\hline & Información de cada órgano no plenario \\
\hline & $\begin{array}{l}\text { Enlaces sitios web y documentos relacionados con } \\
\text { campo de actividad }\end{array}$ \\
\hline & $\begin{array}{l}\text { Composición e información relativa al Grupo } \\
\text { Nacional de la UIP }\end{array}$ \\
\hline
\end{tabular}




\begin{tabular}{|c|c|}
\hline \multirow{7}{*}{ 1.6 Legisladores Puntuación $(0-1)$} & $\begin{array}{l}\text { Lista con datos biográficos y fotografía, e } \\
\text { información participación }\end{array}$ \\
\hline & $\begin{array}{l}\text { Descripción de responsabilidades de } \\
\text { representación y funciones }\end{array}$ \\
\hline & Información de contacto y email \\
\hline & $\begin{array}{l}\text { Actividades como propuestas, preguntas, } \\
\text { mociones, interpelaciones ... }\end{array}$ \\
\hline & Información sobre status del diputado \\
\hline & Datos estadísticos y demográficos \\
\hline & Lista y datos de exdiputados \\
\hline \multirow{2}{*}{$\begin{array}{l}\text { 1.7 Partidos Políticos en el Parlamento } \\
\text { Puntuación }(0-1)\end{array}$} & Lista de partidos políticos con representación \\
\hline & Enlace sitios web de los partidos \\
\hline \multirow{5}{*}{$\begin{array}{l}\text { 1.8 Elecciones y sistemas electorales } \\
\text { Puntuación }(0-1)\end{array}$} & Explicación del procedimiento electoral \\
\hline & Enlace web comité electoral \\
\hline & $\begin{array}{l}\text { Resultados elecciones anteriores por filiación } \\
\text { política y circunscripciones electorales }\end{array}$ \\
\hline & Composición grupos políticos y coaliciones \\
\hline & Resultados elecciones anteriores \\
\hline \multirow{2}{*}{$\begin{array}{l}\text { 1.9 Administración del Parlamento } \\
\text { Puntuación }(0-1)\end{array}$} & $\begin{array}{l}\text { Diagrama/organigrama, funciones y nombre del } \\
\text { Secretario General y jefes de oficina }\end{array}$ \\
\hline & Descripción general de la RPT \\
\hline \multirow{3}{*}{$\begin{array}{l}1.10 \text { Publicaciones, documentos y } \\
\text { servicios de información Puntuación (0-1) }\end{array}$} & $\begin{array}{l}\text { Descripción de tipos y propósitos de publicaciones } \\
\text { y documentos parlamentarios }\end{array}$ \\
\hline & $\begin{array}{l}\text { Información donde y como obtener publicaciones } \\
\text { y documentos del parlamento (vía web y offline) }\end{array}$ \\
\hline & Información sobre biblioteca, archivo y s ${ }^{\circ}$ inf. \\
\hline \multirow{7}{*}{$\begin{array}{l}1.11 \text { Enlaces generales con otros sitios } \\
\text { web Puntuación }(0-1)\end{array}$} & $\begin{array}{l}\text { Presidencia, Gobierno, Tribunal Supremo y Corte } \\
\text { Constitucional }\end{array}$ \\
\hline & Ministerios y organismos nacionales \\
\hline & Parlamentos estatales y autonómicos \\
\hline & $\begin{array}{l}\text { Otras organizaciones parlamentarias regionales, } \\
\text { subregionales e internacionales }\end{array}$ \\
\hline & Unión Interparlamentaria (UIP) \\
\hline & Parlamentos nacionales de otros países \\
\hline & $\begin{array}{l}\text { Enlaces de interés del Parlamento como } \\
\text { representación del pueblo }\end{array}$ \\
\hline \multicolumn{2}{|c|}{$\begin{array}{l}\text { SECCIÓN } 2 \text { - INFORMACIÓN SOBRE ACTIVIDADES LEGISLATIVAS, } \\
\text { PRESUPUESTARIAS Y DE CONTROL }\end{array}$} \\
\hline \multirow{5}{*}{$\begin{array}{l}2.1 \text { Información general sobre } \\
\text { actividades (legislativa, presupuestaria y } \\
\text { de control) Puntuación }(0-1)\end{array}$} & $\begin{array}{l}\text { Calendario de trabajo vigente (legislativo y } \\
\text { control) y de comisiones y pleno con enlaces a } \\
\text { documentos correspondientes }\end{array}$ \\
\hline & $\begin{array}{l}\text { Diagrama desarrollo trabajo parlamentario y } \\
\text { relación con órganos constitutivos }\end{array}$ \\
\hline & $\begin{array}{l}\text { Glosario términos y procedimientos } \\
\text { parlamentarios }\end{array}$ \\
\hline & $\begin{array}{l}\text { Panorama del mecanismo parlamentario y plan de } \\
\text { trabajo habitual }\end{array}$ \\
\hline & $\begin{array}{l}\text { Texto completo del Reglamento, Normas de } \\
\text { Procedimiento y documentos normativos }\end{array}$ \\
\hline
\end{tabular}




\begin{tabular}{|c|c|}
\hline \multirow{6}{*}{ 2.2 Proceso legislativo Puntuación (0-1) } & Explicación proceso legislativo \\
\hline & Texto y estado de todas las leyes propuestas \\
\hline & $\begin{array}{l}\text { Enlaces con documentos del parlamento y } \\
\text { gobierno relacionados con leyes propuestas }\end{array}$ \\
\hline & $\begin{array}{l}\text { Texto y estado final de leyes propuestas en años } \\
\text { anteriores }\end{array}$ \\
\hline & $\begin{array}{l}\text { Textos y acciones llevadas a cabo con respecto a } \\
\text { leyes promulgadas }\end{array}$ \\
\hline & $\begin{array}{l}\text { Base de datos con dispositivo de búsqueda de } \\
\text { proyectos de ley en curso y anteriores y de leyes } \\
\text { promulgadas (véase también 3.1. a-e.) }\end{array}$ \\
\hline \multirow{6}{*}{$\begin{array}{l}2.3 \text { Financiación del presupuesto (la } \\
\text { financiación del presupuesto/ } \\
\text { financiación pública corresponde a la } \\
\text { recepción de ingresos y asignación de } \\
\text { fondos públicos) Puntuación }(0-1)\end{array}$} & $\begin{array}{l}\text { Explicación proceso financiación del presupuesto/ } \\
\text { financiación pública; papel de gobierno y órganos } \\
\text { parlamentarios }\end{array}$ \\
\hline & $\begin{array}{l}\text { Explicación propuesta de financiación del } \\
\text { presupuesto/ financiación pública }\end{array}$ \\
\hline & $\begin{array}{l}\text { Estado examen parlamentario de la propuesta de } \\
\text { financiación del presupuesto/ financiación pública }\end{array}$ \\
\hline & $\begin{array}{l}\text { Documentos de órganos parlamentarios que } \\
\text { examinan y aprueban actividades de financiación } \\
\text { del presupuesto/ financiación pública }\end{array}$ \\
\hline & Documentos sobre presupuestos de años anteriores \\
\hline & $\begin{array}{l}\text { Base de datos con dispositivo de búsqueda de } \\
\text { documentos relativos a la financiación del } \\
\text { presupuesto/ financiación pública (véase también } \\
\text { 3.1. a-e.) }\end{array}$ \\
\hline \multirow{5}{*}{$\begin{array}{l}\text { 2.4 Control (escrutinio) (preguntas, } \\
\text { respuestas, réplicas, declaraciones, } \\
\text { informes de comisiones de investigación, } \\
\text { interpelaciones y debates especiales) } \\
\text { Puntuación }(0-1)\end{array}$} & $\begin{array}{l}\text { Explicación funciones de control y actividades de } \\
\text { órganos }\end{array}$ \\
\hline & Resumen y estado de actividades de control \\
\hline & Documentos de actividades de control \\
\hline & $\begin{array}{l}\text { Documentos de años anteriores relativos a esta } \\
\text { tarea }\end{array}$ \\
\hline & $\begin{array}{l}\text { Base de datos con dispositivo de búsqueda de } \\
\text { documentos actuales y anteriores (véase también } \\
\text { 3.1. a-e.) }\end{array}$ \\
\hline \multirow{5}{*}{$\begin{array}{l}2.5 \text { Actividades de las comisiones y } \\
\text { comités parlamentarios y de otros } \\
\text { órganos no plenarios (considerarse junto } \\
\text { a } 1.5) \text { Puntuación }(0-1)\end{array}$} & $\begin{array}{l}\text { Documentos elaborados por órganos no plenarios, } \\
\text { como calendarios, plan de reuniones, medidas } \\
\text { adoptadas, informes, y documentos }\end{array}$ \\
\hline & $\begin{array}{l}\text { Documentos de años anteriores de órganos no } \\
\text { plenarios }\end{array}$ \\
\hline & Sitios web de órganos no plenarios \\
\hline & $\begin{array}{l}\text { Transmisión radial, televisiva o por Internet de las } \\
\text { reuniones (véase también 3.2. a.) }\end{array}$ \\
\hline & $\begin{array}{l}\text { Archivo sonoro o videoteca de las reuniones } \\
\text { (véase también 3.2. b.) }\end{array}$ \\
\hline \multirow{2}{*}{$\begin{array}{l}\text { 2.6 Actividades plenarias y } \\
\text { documentación Puntuación }(0-1)\end{array}$} & $\begin{array}{l}\text { Documentos elaborados en sesiones plenarias, } \\
\text { como calendarios, plan de reuniones, medidas } \\
\text { adoptadas, declaraciones de diputados, y debates }\end{array}$ \\
\hline & $\begin{array}{l}\text { Documentos de sesiones plenarias de años } \\
\text { anteriores }\end{array}$ \\
\hline
\end{tabular}




\begin{tabular}{|c|c|}
\hline & $\begin{array}{l}\text { Transmisión radial, televisiva o por Internet de las } \\
\text { reuniones plenarias (véase también } 3.2 \text {. a.) }\end{array}$ \\
\hline & $\begin{array}{l}\text { Archivo sonoro o videoteca de las reuniones } \\
\text { plenarias (véase también 3.2. b.) }\end{array}$ \\
\hline $\begin{array}{l}\text { SECCIÓN } 3 \text { - HERRAMIENTAS: BÚ } \\
\text { INFORMACIÓN }\end{array}$ & QUEDA, RECEPCIÓN Y VISUALIZACIÓN DE \\
\hline & $\begin{array}{l}\text { Buscar y visualizar documentos e información del } \\
\text { Parlamento (secciones } 1 \text { y } 2 \text { ) }\end{array}$ \\
\hline & $\begin{array}{l}\text { Buscar elementos como palabras en texto, estado } \\
\text { de una ley, fechas de acciones, diputados, } \\
\text { comisiones, partidos políticos y otros } \\
\text { componentes }\end{array}$ \\
\hline 3.1 Motor de búsqueda Puntuación $(0-1)$ & Clasificar resultados según diversos criterios \\
\hline & $\begin{array}{l}\text { Atender a necesidades de los parlamentarios, } \\
\text { personal, público en general, y ser comprensible } \\
\text { tanto para profesionales como principiantes }\end{array}$ \\
\hline & $\begin{array}{l}\text { Enlazar resultados de búsqueda de documentos } \\
\text { con registros de video y audio relacionados }\end{array}$ \\
\hline 3.2 Transmisión por radio, televisión e & $\begin{array}{l}\text { Capacidad transmitir por radio, televisión o } \\
\text { Internet reuniones en directo de cualquier órgano } \\
\text { parlamentario, así como eventos y programas } \\
\text { parlamentarios }\end{array}$ \\
\hline & $\begin{array}{l}\text { Archivo de reuniones, eventos y programas } \\
\text { trasmitidos por radio, televisión o Internet vistos } \\
\text { "a demanda" }\end{array}$ \\
\hline 3.3 Servicio de alertas Puntuación (0-1) & $\begin{array}{l}\text { Servicios de alerta, tales como correo electrónico, } \\
\text { agregadotes RSS y otras tecnologías que permiten } \\
\text { informarse de acciones importantes del } \\
\text { Parlamento }\end{array}$ \\
\hline 3.4 Servicios móviles Puntuación $(0-1)$ & $\begin{array}{l}\text { Servicios que permiten a legisladores y público } \\
\text { acceder a información y documentos del sitio web } \\
\text { en dispositivos móviles }\end{array}$ \\
\hline 3.5 Seguridad y autentificación & $\begin{array}{l}\text { Servicios seguros que permiten a miembros del } \\
\text { Parlamento el acceso a información y documentos } \\
\text { confidenciales }\end{array}$ \\
\hline Puntuación (0-1) & $\begin{array}{l}\text { Servicio de autentificación como firmas digitales } \\
\text { que verifican la autenticidad de los documentos e } \\
\text { información }\end{array}$ \\
\hline $\begin{array}{l}\text { SECCIÓN } 4 \text { - HERRAMIENTAS: CC } \\
\text { CIUDADANOS }\end{array}$ & UNICACIÓN Y DIÁLOGO CON LOS \\
\hline & $\begin{array}{l}\text { Herramienta para que usuarios puedan enviar } \\
\text { comentarios y hacer preguntas sobre el sitio web }\end{array}$ \\
\hline $\begin{array}{l}\text { 4.1 Comentarios y opiniones Puntuación } \\
(0-1)\end{array}$ & $\begin{array}{l}\text { Información sobre posibilidades y vías } \\
\text { recomendadas para contactar con diputados, } \\
\text { comisiones, funcionarios (correos electrónicos, } \\
\text { teléfonos, internet) }\end{array}$ \\
\hline $\begin{array}{l}\text { 4.2 Comunicación entre diputados y } \\
\text { ciudadanos Puntuación }(0-1)\end{array}$ & $\begin{array}{l}\text { Posibilidad de contactar con diputados, } \\
\text { comisiones y funcionarios mediante correos } \\
\text { electrónicos no estructurados o formularios } \\
\text { electrónicos }\end{array}$ \\
\hline
\end{tabular}




\begin{tabular}{|c|c|}
\hline & $\begin{array}{l}\text { Herramienta que permita a diputados, comisiones, } \\
\text { funcionarios recibir, administrar y responder a } \\
\text { correos electrónicos de ciudadanos y sociedad } \\
\text { civil }\end{array}$ \\
\hline & $\begin{array}{l}\text { Herramientas interactivas (blogs, foros y debates } \\
\text { en línea, peticiones electrónicas) para interactuar } \\
\text { con ciudadanos }\end{array}$ \\
\hline & $\begin{array}{l}\text { Sistemas que permitan votaciones en línea cuando } \\
\text { el tema sea importante y los resultados útiles }\end{array}$ \\
\hline & $\begin{array}{l}\text { Prueba y aplicación de nuevos métodos de } \\
\text { interacción entra la ciudadanía y el parlamento } \\
\text { según vayan saliendo }\end{array}$ \\
\hline SECCIÓN 5 - DISEÑO: USABILIDA & ACCESIBILIDAD E IDIOMA \\
\hline 51 Usahilidad Punturión $(0-1)$ & $\begin{array}{l}\text { Elementos de diseño y opciones derivadas de una } \\
\text { visión integradora teniendo en cuenta diferentes tareas, } \\
\text { requisitos y perfiles de usuarios }\end{array}$ \\
\hline 5.1 Usabilidad Puntuacion $(0-1)$ & $\begin{array}{l}\text { Pruebas realizadas por usuarios y otros métodos de } \\
\text { usabilidad para que el sitio web sea comprensible } \\
\text { desde un principio }\end{array}$ \\
\hline $\begin{array}{l}\text { 5.2 Normas de accesibilidad Puntuación } \\
(0-1)\end{array}$ & $\begin{array}{l}\text { Estándares de la W3C u otros estándares para que } \\
\text { el sitio web sea usado por personas con } \\
\text { discapacidad }\end{array}$ \\
\hline & $\begin{array}{l}\text { Caso de varios idiomas oficiales, esfuerzos para } \\
\text { que todos los contenidos estén disponibles en } \\
\text { dichos idiomas }\end{array}$ \\
\hline 5.3 Idiomas Puntuación (0-1) & $\begin{array}{l}\text { Si solo se hace revisión parcial en otro idioma } \\
\text { debe centrar atención en: inf. Básica y resumen } \\
\text { periódico de actividades ordinarias }\end{array}$ \\
\hline & $\begin{array}{l}\text { Versión completa o parcial del sitio en idioma } \\
\text { utilizado en comunicación internacional }\end{array}$ \\
\hline $\begin{array}{l}\text { 5.4 Elementos generales del diseño } \\
\text { Puntuación }(0-1)\end{array}$ & $\begin{array}{l}\text { Poner a disposición de usuarios elementos como: } \\
\text { preguntas frecuentes; novedades: mapa del sitio: } \\
\text { autoría del sitio y datos relevantes; ayuda: persona } \\
\text { de atención sobre el funcionamiento; guía para } \\
\text { realizar búsquedas }\end{array}$ \\
\hline & $\begin{array}{l}\text { Soporte de múltiples navegadores y garantía de } \\
\text { compatibilidad sin impedir introducción de } \\
\text { innovaciones }\end{array}$ \\
\hline
\end{tabular}

